\title{
Variation of Structure and Optical Material Dispersion in Lead Borate Glass Containing Multi Valence Chromium and Germanium Cations.
}

Fathy El-Sayed Abdel-Wahab ( $\sim$ fabdelwahab@sci.asu.edu.eg )

Ain Shams University Faculty of Science https://orcid.org/0000-0001-7545-3088

Fouad El-Diasty

Ain Shams University Faculty of Science

Manal Abdel-Baki

National Research Centre

Heba Abdelmaksoud

Ain Shams University Faculty of Science

\section{Research Article}

Keywords: Lead borate glasses, FTIR spectrum, none bridging Oxygen, optical properties, wavelength at zero material dispersion

Posted Date: July 2nd, 2021

DOI: https://doi.org/10.21203/rs.3.rs-645450/v1

License: (9) This work is licensed under a Creative Commons Attribution 4.0 International License. Read Full License 


\title{
Variation of structure and optical material dispersion in lead borate glass containing multi valence Chromium and Germanium cations.
}

\author{
Fathy Abdel-Wahab ${ }^{1 *}$, Fouad El-Diasty ${ }^{1}$, Manal Abdel-Baki ${ }^{2}$ and Heba AbdelMaksoud ${ }^{1}$ \\ ${ }^{1}$ Physics Department, Faculty of Science, Ain Shams University, Cairo 11566 Egypt \\ ${ }^{2}$ Glass Research Department, National Research Center, Dokki, Cairo Egypt
}

\begin{abstract}
In pursuit of manufacturing glass having a high refractive index and low dispersion, a series of lead and borate glasses containing germanium and chromium oxide by composition $25 \mathrm{~B}_{2} \mathrm{O}_{3}-73.8 \mathrm{PbO}-x \mathrm{GeO}_{2}-(1.2-x) \mathrm{Cr}_{2} \mathrm{O}_{3}$, with $0 \leq x \leq 1.2 \mathrm{~mol} \%$, are prepared. IR measurements are carried out to explore the structure of as-prepared samples. The deconvoluted IR peaks revealed presence of bridging Oxygen up to $x=0.6$ mole \%. At $x>0.6$ mole $\%$ none bridging Oxygen is the dominant. The dependence of the measured hydrostatic density and corresponding molar volume for the studied compositions are analyzed and discussed. The dispersion curves of refractive index $(n)$ and absorption index $(k)$ are calculated in the spectral range 300$2500 \mathrm{~nm}$. The effect of increasing the ratio $\mathrm{GeO}_{2} /\left[\mathrm{GeO}_{2}+\mathrm{Cr}_{2} \mathrm{O}_{3}\right]$ on the calculated dispersion energy, lattice energy, oscillator energy and material dispersion are deduced. For photonic applications, the wavelength at zero material dispersion for the investigated samples is calculated and compared with other systems based on Borates, silicates and Germinate fiber. The results recommend that the present glass could be used in different modern optoelectronics devices.
\end{abstract}

Keywords: Lead borate glasses; FTIR spectrum; none bridging Oxygen; optical properties; wavelength at zero material dispersion.

1. Introduction

The accelerated use of infrared spectrum of light has led to the development of new optical materials for several advanced optical devices and systems. Photonics, where light can be controlled by light, is a superior example of these highly developed applications. In the core of photonic technologies lie the refractive indices of the used materials (Abdel-Baki and El-Diasty 2013). Photonic devices such as ultrafast optical switches, power limiters, real time holography, self-focusing, white-light continuum generation need exploitation of glasses with higher nonlinear index of refraction, 
materials which have high refractive index, high damage threshold and a large region of high transparency. Low light scattering loss is expected in oxide glasses because they have lower glass transition temperature. In addition, oxide glasses with mixed cation compositions are thermally stable and have controllable refractive index variation. In this regard, borate glass is considered as one of the most popular and excellent glass forming materials (Abdel-Baki et al. 2007). The profits of using $\mathrm{B}_{2} \mathrm{O}_{3}$ in glass formation are reduction of melting temperature, increased thermal stability and mechanical strength, and enhanced chemical durability. Borate glasses contain $\pi$ electron on the $\mathrm{B}-\mathrm{O}$ ring, thus considerable values for their optical nonlinearity is expected (El-Diasty et al. 2009). $\mathrm{GeO}_{2}$-based glasses are transparent in the near infrared region and have a lower glass transition temperature, $T_{g}$, and lower phonon energy than $\mathrm{SiO}_{2}$-based glasses. Borate glasses doped by chromium ions showed large optical nonlinearity due to the large hyper-polarizability of $\mathrm{Cr}_{2} \mathrm{O}_{3}$ (Abdel Wahab et al. 2009). Glasses containing cations such as $\mathrm{Pb}^{2+}$ with an outer electron shell of $18+2$ electrons should have higher polarizabilities and lower melting temperatures (ElDiasty et al. 2014). Lead-germanium glasses are good transmission in the IR region up to $4.5 \mathrm{~mm}$ and are promising materials for applications such as lasing materials, up converting phosphors, and optical waveguides (Balda et al. 2000).

In the present work, the structural changes due to introducing germanium oxide on the expense of chromium oxide in lead borate network are recorded using FTIR measurements in the wave number range $400-1400 \mathrm{~cm}^{-1}$. Indeed, the measured hydrostatic density as a sensitive parameter for structural changes is measured with corresponding calculated molar volume. The dependence of linear optical parameters such as energy gap, Urbach energy and number of oscillating dipoles on the molar ratio of $\mathrm{GeO}_{2} /\left[\mathrm{GeO}_{2}+\mathrm{Cr}_{2} \mathrm{O}_{3}\right]$ are also evaluated. On the other hand, the calculated material dispersion together with the inter-band parameters is used to appraise wavelength at zero material dispersion which illustrate function of the studied compositions in the field data communication through optical fiber.

\section{Experimental}

A series of lead borate glasses of compositions $25 \mathrm{~B}_{2} \mathrm{O}_{3}-73.8 \mathrm{PbO}-x \mathrm{GeO}_{2}-(1.2-x)$ $\mathrm{Cr}_{2} \mathrm{O}_{3}(0 \leq x \leq 1.2 \mathrm{~mol} \%)$ as listed in table are prepared. The used materials were of chemically pure grade, in the form of $\mathrm{H}_{3} \mathrm{BO}_{3}, \mathrm{~Pb}_{3} \mathrm{O}_{4}, \mathrm{Cr}_{2} \mathrm{O}_{3}$ and $\mathrm{GeO}_{2}$. The glass is prepared by melt quenching technique using platinum $2 \%$ rhodium crucibles in an 
electric furnace. The amount of the glass batch was $50 \mathrm{~g} / \mathrm{melt}$. The batch was preheated at $500-600{ }^{\circ} \mathrm{C}$ for almost an hour to evaporate the carbonates. The temperature of melting was $950-1000{ }^{\circ} \mathrm{C}$, the duration of melting was one hour after the last traces of batches were disappeared. The glass melt was continuing stirred during the preparation to avoid the presence of air micro bubbles. Then the melt was poured onto stainless steel mould and annealed at around $350{ }^{\circ} \mathrm{C}$ to remove the thermal strains. Transparent glass slabs were prepared by grinding and polishing of the prepared samples with paraffin oil and minimum amount of water. The thickness of the glass slabs was about $3 \mathrm{~mm}$. Polishing was completed with stannic oxide and paraffin to reach a surface roughness less than $\lambda / 3$, where $\lambda$ is the wavelength. The surface roughness was tested by interferometric method. Infrared absorption measurements are carried out at room temperature by drying and grounding the investigated glass. The obtained powder is mixed with potassium bromide and grounded again to obtain homogeneous mixture. The mixture is then pressed mechanically at $70 \mathrm{MPa}$ pressure in the form of discs.

The hydrostatic density of the investigated samples is measured by Archimedes principle at room temperature using xylene as an immersion liquid.

Two beam spectrophotometer model JASCO $670 \mathrm{UV}-\mathrm{Vis}-\mathrm{NIR}$ is used to measure reflectance and transmittance coefficients of as prepared optical slabs. With sampling interval $2 \mathrm{~nm}$ and resolution limit of 0.2 , the accuracy of measuring $T(\lambda)$ and $R(\lambda)$ is 0.004. All optical measurements are carried out at room temperature and in the entire spectral range $200-2500 \mathrm{~nm}$.

\section{Results and discussion}

\subsection{FTIR measurements}

The FTIR spectrum of the investigated compositions is shown in Fig. (1). The obtained absorption peaks of the FTIR spectrum show many features, as $x$ increases from 0 to1.2 mole\%, which are related to the structural aspects from which it can be seen as follows: The spectrum consist mainly of four main regions which are positioned in the ranges $407-554 \mathrm{~cm}^{-1}, 611-782 \mathrm{~cm}^{-1}, 786-1131 \mathrm{~cm}^{-1}$ and $1131-1500$ $\mathrm{cm}^{-1}$ (Abdel-Baki et al. 2007). The peak detected in the first region and lie in the range $470-484 \mathrm{~cm}^{-1}$ may be due to the presence of metallic ions such as $\mathrm{Pb}$ and $\mathrm{Ge}$, the symmetric bending vibration mode of $\mathrm{Pb}-\mathrm{O}$ in $\mathrm{PbO}_{4}$ (Moustafa et al. 1994; Culea et 
al. 2010; Narendrudu et al. 2016; Reddy et al. 2006; Khanna 2000), and Ge-O-Ge symmetric stretching vibrations (Gowda and Anavekar 2004; Chelcea et al. 2011). In this region a band due to $\mathrm{CrO}_{4}^{2-}$ structural units is also possible (Chelcea et al. 2011). The observed peaks in the second region at $708-713 \mathrm{~cm}^{-1}$ are attributed to the combined vibrations of the $\mathrm{BO}_{3}$ (Vijay et al. 2015) and $\mathrm{PbO}_{4}$ groups (Varshneya 1994), bending vibration of the B-O-B linkage in the borate network (ElBatal et al. 2014; Kamitsos et al. 1987, 1981), and the stretching mode of Ge-O-Ge bonds in $\mathrm{GeO}_{6}$ units (Narendrudu et al. 2016; Tenny and Wong 1972).

The absorption peak observed at $875-893 \mathrm{~cm}^{-1}$, is assigned to B-O bond stretching of $\mathrm{BO}_{4}$ (Doweidar et al. 2013; Iordanova et al. 1994) overlapped with asymmetric stretching vibration of $\mathrm{CrO}_{4}^{2-}$ structural unit (Doweidar and Saddeek 2010). While the peak centered at about $1000 \mathrm{~cm}^{-1}$, is assigned to penta-borate group (Doweidar and Saddeek 2010) and B-O-Pb vibrations. This peak shifts toward lower energy with increasing $\mathrm{GeO}_{2}$ content. The band centered at about $1208-1240 \mathrm{~cm}^{-1}$, is assigned to asymmetric stretching vibrations of $\mathrm{B}-\mathrm{O}$ bond of triangular $\left[\mathrm{BO}_{3}\right]$ present in orthoborate group (Iordanova et al. 1994) and shifts toward lower wave number with the increase in $\mathrm{GeO}_{2}$ content. The band centered at about $1310 \mathrm{~cm}^{-1}$ is attributed to the presence of pyro-borate, ortho-borate groups contain $\mathrm{BO}_{3}$ (Doweidar and Oraby 1997; Kim and and Bray 1976; Bray and O'Keefe 1963) and disappeared at $x>0.8$ mole \%. The absorption peak appeared in the wave number range $1384-1391 \mathrm{~cm}^{-1}$ possibly due to the asymmetric relaxation of the $\mathrm{B}-\mathrm{O}$ bond of the triangular $\left[\mathrm{BO}_{3}\right]$ units (Varshneya 1994; ElBatal et al. 2014; Kamitsos et al. 1987, 1981; Doweidar and Oraby 1997) stretching vibrations of the borate triangles with non-bridging oxygen (NBO) in various borate groups (Chelcea et al. 2011), and the asymmetric stretching vibration modes of Ge-O-Ge bonds (Narendrudu et al. 2016). Moreover, in Fig. (1) the intensity of the third region decreases as $x$ increase from $x=0.0$ mole $\%\left(\mathrm{GeO}_{2}=0\right.$, $\left.\mathrm{Cr}_{2} \mathrm{O}_{3}=1.2\right)$ to $x=0.2$ mole $\%\left(\mathrm{GeO}_{2}=0.2, \mathrm{Cr}_{2} \mathrm{O}_{3}=1.0\right)$ and increases in intensity for $x>$ 0.2 . On the other hand, the broadness of band at $1200-1500 \mathrm{~cm}^{-1}$ decrease as $x$ varies from 0.0 to 1.2 mole $\%$.

Quantitative analysis of the spectrum shown in Fig. (1) is attained by calculating N4 which represents the ratio of $\mathrm{BO}_{4}$ tetrahedral units to the total concentration of boron atoms in the studied glass i.e., $\mathrm{N} 4=$ concentration of $\mathrm{BO}_{4} /$ total concentration of 
$\left(\mathrm{BO}_{3}+\mathrm{BO}_{4}\right)$ units (Kim and Bray 1976). This was done by deconvoluting IR absorbance peaks shown in Fig. (1). It should be noted that the deconvolution process is used to separate broad bands of the IR spectrum into its several symmetrical Gaussian bands by considering the position and area of each band related to the vibrations of a particular structural unit. The deconvolution process was applied on the investigated samples by sub-dividing the spectrum of each composition into different spectral regions and then fitting each band with Gaussian function. The area and the position of each Gaussian peak are recorded for quantitative analysis of the measured spectrum (Bray and O'Keefe 1963). The area under absorption peak is considered to be proportional to the concentration of structural units emerging it Figure (2) illustrates the deconvoluted IR peaks for the studied compositions $25 \mathrm{~B}_{2} \mathrm{O}_{3}$ $73.8 \mathrm{PbO}-x \mathrm{GeO}_{2}-(1.2-x) \mathrm{Cr}_{2} \mathrm{O}_{3}$ with $x=0.0,0.6$ and 1.2 (as an example). The dependence of the calculated $\mathrm{N} 4$ on the molar ratio of $\mathrm{GeO}_{2} /\left[\mathrm{GeO}_{2}+\mathrm{Cr}_{2} \mathrm{O}_{3}\right]$ is illustrated in Fig. (3). This figure demonstrates that increasing the molar ratio of $\mathrm{GeO}_{2}$ from zero (sample (1)) up to 0.2 (sample (2)) and at $x=1.0$ (sample (6)) and $x=1.2$ mole \% (sample (7)) N4 does not change against composition. For $\mathrm{GeO}_{2}>0.2$ mole $\%, \mathrm{~N} 4$ increases to maximum at $x=0.6$ mole $\%$ of $\mathrm{GeO}_{2}$ followed by a decrease as the ratio increase up to 0.8 mole $\%$. This means that increasing $\mathrm{GeO}_{2}$ content in lead borate host network in the range of $\mathrm{GeO}_{2}=0.2-0.6$ mole $\%$ increases the number of bridging oxygen (BO). Above $x=0.6$ mole $\%, \mathrm{~N} 4$ decreases as $\mathrm{GeO}_{2}$ increase to 0.8 mole \%. This means increasing of non-bridging Oxygen (NBO) in the lead-borate network over the ratio of bridging Oxygen. Similar behavior of N4 is observed in lead borate network using NMR measurements (Doweidar et al. 2013; Iordanova et al. 1994; Doweidar and Saddeek 2010; Doweidar and Oraby 1997; Kim and Bray 1976; Bray and O'Keefe 1963). These measurements clarified that introduction of $\mathrm{PbO}$ from 10 up $50 \%$, the fraction of four coordinated boron atoms $\left[\mathrm{BO}_{4}\right]$ increase over three coordinated boron atoms $\left[\mathrm{BO}_{3}\right]$. Further increase of $\mathrm{PbO}$ over $50 \%$ decreases the number of $\left[\mathrm{BO}_{4}\right]$ with anomalous point at $50 \%$ of $\mathrm{PbO}$ (Leventhal and Bray 1965). Furthermore, the same trend of Fig. (3) is also observed in the literature for many $\mathrm{B}_{2} \mathrm{O}_{3}$ oxide glasses (Priven 2000).

\subsection{Hydrostatic density and molar volume}

Measurement of hydrostatic density is considered as an important tool to investigate the structural compactness and the variation of dimensions of interstitial holes. Figure 
(4a) shows the dependence of the measured hydrostatic density as function of $\mathrm{GeO}_{2} /\left[\mathrm{GeO}_{2}+\mathrm{Cr}_{2} \mathrm{O}_{3}\right]$ molar ratio in lead-Borate network for the studied samples. This figure demonstrates that the density shows an oscillatory behavior against the increase of $\mathrm{GeO}_{2}$. Furthermore, this figure shows that increasing $\mathrm{GeO}_{2}$ with ratio 0.2 mole \% (sample (2)) increased the density followed by a decrease to minimum density when $\mathrm{GeO}_{2}$ content ratio is increased to 0.4 mole \% (sample (3)). In addition, for sample (4) $\left(x=0.6\right.$ mole \%) the density increases by ratio $20 \%$. Increasing $\mathrm{GeO}_{2}$ beyond $0.6 \%$ has a little effect on the density.

The molar volume of glass composition could be calculated using the following equation $V_{m}=\sum_{i} x_{i} M_{i} / \rho$, where $M_{i}$ is the molecular weight and $x_{\mathrm{i}}$ is the molar fraction of the $i^{\text {th }}$ component of the studied compositions. The calculated molar volume, $V_{m}$, as function of the content of $\mathrm{GeO}_{2}$ on the expense of $\mathrm{Cr}_{2} \mathrm{O}_{3}$ in the studied network of $\mathrm{PbO}-\mathrm{B}_{2} \mathrm{O}_{3}$ is shown Fig. (4b). This figure shows that introduction of $\mathrm{GeO}_{2}$ in the host Lead-Borate network in the studied composition range ( $x=0-1.2$ mole \%) produces a reverse trend to that obtained in Fig. (4a).

The anomalous behavior observed in Fig. (4) which is due to replacement of $\mathrm{Cr}_{2} \mathrm{O}_{3}$ with $\mathrm{GeO}_{2}$ in the investigated $\mathrm{PbO}-\mathrm{B}_{2} \mathrm{O}_{3}$ glass could be explained as follows: It is known that the structure of Lead Borate network which is rich in lead (as the investigated case) consists mainly of two sub-networks realized by Bray et al. (1963, 1992) and Takaishi et al. (2000). The first sub-group is for Borate oxide network and is composed of two building blocks normal triangle coordination $\left(\mathrm{BO}_{3}^{0}\right)$ and fourfold tetrahedral coordination $\left(\mathrm{BO}_{4}^{-}\right)$which are connected together through Oxygen atom to form B-O-B (Borate bridging Oxygen). Indeed, the second sub-network contains triangle coordination pyramids $\mathrm{PbO}_{3}$ which are linked to each other by Oxygen atoms to form Borate bridging Oxygen $\mathrm{P}-\mathrm{O}-\mathrm{P}$. The building block $\mathrm{PbO}_{3}$ is also observed in PbO-SiO 2 composition (Takaishi et al. 2000; Imaoka et al. 1986). These two subnetworks are linked together via fourfold tetrahedral coordination tetrahedral of Borate network to develop P-O-B covalent bonds (El-Diasty et al. 2014).

The transition metal such as Chromium can exit in host network by two oxidation states where, $\mathrm{Cr}^{3+}$ which act as a modifier while $\mathrm{Cr}^{6+}$ plays the role of former with $\mathrm{CrO}_{4}^{2-}$ building unit (Abdel-Baki et al. 2007). Chromium as a former converts not only $\mathrm{BO}_{3}$ building units to $\mathrm{BO}_{4}$ but also $\mathrm{PbO}_{3}$ into $\mathrm{PbO}_{4}$ (Warren 1941; Wang et al. 
1991; Rada et al. 2013). This conversion process increases the number of bridging oxygen (BO) and consequently increases the compactness of the studied $\mathrm{PbO}-\mathrm{B}_{2} \mathrm{O}_{3}$ network accompanied by a decrease in its molar volume (Fig. 4). On the other hand, $\mathrm{GeO}_{2}$ enters the host network with $\mathrm{GeO}_{4}$ unit which has a role of former (Vijay et al. 2015). Introducing $\mathrm{GeO}_{2}$ by 0.2 mole \% (sample 2) increases the density due to creation of bridging Oxygen which causes a decrease of the molar volume. Definitely it is also argued to presence of two formers $\mathrm{Cr}^{6+}$ and $\mathrm{GeO}_{4}$ at the same time in the structural network of Lead-Borate. Reducing molar fraction of $\mathrm{Cr}_{2} \mathrm{O}_{3}$ to 0.8 mole \% (sample (3)) causes the valence of $\mathrm{Cr}^{6+}$ to decrease to lower valence, which means appearance of its role as a modifier $\left(\mathrm{Cr}^{3+}\right)$ which indicates a creation of non-bridging Oxygen (NBO) and partial transformation of $\mathrm{BO}_{4}$ into $\mathrm{BO}_{3}$ and $\mathrm{PO}_{4}$ into $\mathrm{PO}_{3}$ structural units. Part of this transformation is compensated due to presence of $\mathrm{GeO}_{2}$ in the host network. This partial compensation takes place as a result of its role as a former (Vijay et al. 2015). After that increasing ratio of $\mathrm{GeO}_{2}$ content not only eliminate the former role of Chromium but also transforms $\mathrm{GeO}_{4}$ into $\mathrm{GeO}_{6}$ and also transformation of $\mathrm{BO}_{3}$ and $\mathrm{PbO}_{3}$ into $\mathrm{BO}_{4}$ and $\mathrm{PbO}_{4}$ in sequence.

\subsection{Optical dispersion:}

Figure (5) shows the dependence of the measured transmittance, $T(\lambda)$, on the applied wavelength for the studied samples. In this figure transmittance exhibit one deep depression in the UV and visible regions of spectrum. Furthermore, an increase in the magnitude of $T$ is seen as $\mathrm{GeO}_{2}$ content increases up to sample (2) followed by a decrease for samples (3). As $x>0.6$ mole $\%$ causes an increase in the magnitude of $T$.

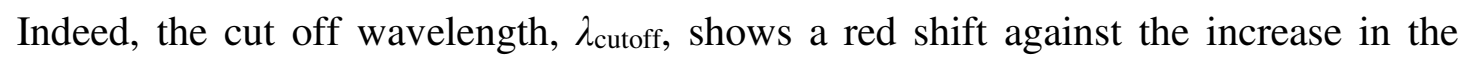
$\mathrm{GeO}_{2}$ content from 0.0 mole \% (sample (1)) up to 0.6 mole \% (sample (4)) and a decrease of $\mathrm{Cr}_{2} \mathrm{O}_{3}$ with the same ratio. The red shift is due to conversion of bridging Oxygen $[\mathrm{BO}]$ to non-bridging bonds $[\mathrm{NBO}]$, i.e., $[\mathrm{BO}]_{4 / 2}^{-}$into $[\mathrm{BO}]_{3 / 2}^{-}$bonds. The negative charge on the $[\mathrm{BO}]_{3 / 2}^{-}$building unit increases the density of states above the valence band which alters optical energy gap. Ultraviolet shift is observed for samples (5) and (6) due to growth role of $\mathrm{GeO}_{6}$ as a former which transforms non bridging Oxygen $[\mathrm{NBO}]$ to bridging Oxygen $[\mathrm{BO}]$, i.e., $[\mathrm{BO}]_{3 / 2}^{-}$into $[\mathrm{BO}]_{4 / 2}^{-}$building units (Abdel-Baki et al. 2007). 


\subsection{Evaluation of optical constants and data reduction}

A method of data reduction based on an iteration technique (Khashan and El-Naggar 2000 ) is used to calculate precisely the attenuation factor $\eta$ which represents the modifications caused to the electromagnetic wave, during its propagation in the material of refractive index $n$ and absorption index $k$. The attenuation factor is given by $\eta=\exp (-\alpha d)$ where $d$ is the sample thickness and $\alpha$ is the absorption coefficient of the sample, $\alpha=\frac{4 \pi k}{\lambda}$. The real part, $n$, of the complex dielectric constant $n$-ik is given by (Khashan and El-Naggar 2000),

$$
n=\frac{1+R_{s}}{1-R_{s}}+\sqrt{\frac{4 R_{s}}{\left(1-R_{s}\right)^{2}}-k^{2}}
$$

Where $R_{\mathrm{S}}$ is the interface reflection coefficient. As a first iteration $\eta$ is taken as a unity. A rough value of $R_{\mathrm{S}}$ and $T_{\mathrm{s}}$ are obtained using the following relations (Khashan and El-Naggar 2000), $R_{s}=\frac{R}{1+\eta T}$ and $T_{s}=\sqrt{\frac{\left(1-\eta^{2} R_{s}^{2}\right) T}{\eta}}$ where $T$ and $R$ are the measured transmittance and reflectance. The obtained values of $R_{\mathrm{S}}$ and $T_{\mathrm{s}}$ are used to obtain a rough value of absorbance $A_{\mathrm{t}}(\lambda)=1-\left(R_{\mathrm{S}}+T_{\mathrm{S}}\right)$ which gives the new second value of $\eta\left(\eta=1-A_{\mathrm{t}}\right)$. The new value of $\eta$ is used once more to calculate new values of $R_{\mathrm{s}}$ and $T_{\mathrm{s}}$ as done previously. The iteration is repeated many times until a constant function of $A_{t}$ does not change its values appreciably as new value of attenuation factor are obtained. The attained final values of $\eta$ together with the applied wavelength and sample thickness $d$ are used to calculate value of the absorption index $k$ using the following equation (Khashan and El-Naggar 2000),

$$
k=-\left(\frac{\lambda}{4 \pi d}\right) \ln \eta
$$

Furthermore, the achieved final value of $\eta$ jointly the corresponding values of $R_{\mathrm{s}}$ and $k$ (eq.(2)) are substituted in eq. (1) to yield the refractive index $n$ at a given wavelength. The calculated refractive index $(n)$ through studied spectral range for each of the investigated compositions is shown in figure (6). In the whole spectrum a remarkable increase of the refractive index takes place from sample (1) up to sample (4) followed by a decrease in magnitude for samples (5) and (6). This trend may be due to the variation in the measured hydrostatic density (Fig. (4)) of the samples besides the high bond polarizability of $\mathrm{Cr}^{3+}$ which shows a direct proportionality with refractive index (El-Diasty et al. 2006). The observed increase of N4 between samples (1) and (4) as 
shown in Fig. (3) is an evidence to the decrease of $\mathrm{Cr}^{3+}$ and its high bond polarizability which plays a role of modifier and also presence of $\mathrm{GeO}^{4+}$ as a former which lead to the increase of refractive index. On the other hand, the decrease of N4 between samples (4) and (7) means a more transformation of $\mathrm{Cr}^{6+}$ into decrease of $\mathrm{Cr}^{3+}$ and transformation of $\mathrm{GeO}_{4}$ into $\mathrm{GeO}_{6}$. The conversion of $\mathrm{GeO}_{4}$ into $\mathrm{GeO}_{6}$ increases its role as a former which in turn modify the refractive index as observed in Fig. (6).

\subsection{Optical band gap parameters measurements}

Concerning to Tauc's theory (Tauc 1974), the optical band gap energy for direct and indirect transitions determined, Fig. (7), with an error in the order of $0.02 \mathrm{eV}$, using the formula:

$$
\alpha(h v)=\alpha_{o}\left[\frac{\left(h v-E_{g}\right)^{r}}{h v}\right]
$$

where $\alpha_{\mathrm{o}}$ is a temperature independent constant related to the extent of the band tailing, $v$ is the light frequency, $h$ is Planck's constant. In eq. (3) the exponent $r=0.5$ for allowed direct transition and $r=2$ for indirect one. The obtained values of the direct, $E_{g}^{d i r}$ and indirect, $E_{g}^{\text {indir }}$ band gap energies as a function of glass compositions are shown in Fig. (8a) and listed in table (1).

\subsubsection{Width of localized band tail states}

The width of the band tail localized states could be evaluated using Urbach energy, $E_{\mathrm{U}}$ which could be calculated from the slope of the linear part of $\ln \alpha$ against photon energy as:

$$
\ln \alpha=\text { cons } \tan t+\frac{h v}{E_{U}}
$$

Where $\alpha$ is the optical absorption coefficient and $h v$ is the photon energy. The calculated values of $E_{\mathrm{U}}$ are shown in Fig, (8b) and inserted in table (1). In this figure, the width of the localized states band tail illustrates a decrease of $E_{\mathrm{U}}$ as a general trend against the increase of $\mathrm{GeO}_{2}$ on the expense of $\mathrm{Cr}_{2} \mathrm{O}_{3}$. This behavior could be explained as follows: the Oxygen dangling bond or non-bridging Oxygen [NBO] is a localized structural defect and compose of one half of the permanent broken Oxygen 
bond (Skuja 1998; Vaccaro 2009). These defects are formed in the host network by introduction of a modifier cation such as $\mathrm{Cr}^{3+}$ (as present study).The modifier ions break the connected building blocks through Oxygen bond to create Non-bridging Oxygen defect. The negative Oxygen bonds create a state in the pseudo energy gap. The energy position and density of these states depends on density of NBO defects (Abdel-Wahab et al. 2018). Therefore, the decrease of the width of localized states shown in Fig. (8b) against composition means a decrease of number of non-bridging Oxygen and an increase of bridging Oxygen which is due to the conversion of $\mathrm{BO}^{3+}$ into $\mathrm{BO}^{4+}$ in the host structural network. Furthermore, the decrease of the density of states in energy gap explains the increase of the optical energy gaps illustrated in Fig. (8a).

\subsubsection{Position of the Fermi level}

The dispersion of the extinction coefficient $k(\lambda)$ could be used to evaluate the energy position of the Fermi level by applying Fermi-Dirac distribution function (Khashan and El-Naggar 2000) of the form:

$$
k(E)=\frac{1}{1+\exp \left(\frac{E-E_{F}}{K_{B} T}\right)}
$$

Where $k(E)$ is the maximum value of absorption index, $E_{\mathrm{F}}$ is the energy position of Fermi level, $E$ is the photon energy, $K_{\mathrm{B}}$ the Boltzmann constant and $T$ is the absolute temperature. Equation (5) could be rearranged to yield:

$$
K_{B} T \ln \left[\frac{1-k(E)}{k(E)}\right]=E-E_{F}
$$

Plotting the left hand side of eq. (6) as function of $E$ yields a curve. Extrapolating the straight part of the curve to $x$-axis at $y=0$ will give value of $E_{\mathrm{F}}$. The calculated values of $E_{F}$ as function of composition are added to table (1). The relative high value of $E_{F}$ indicates that the studied glass compositions behave like an insulator.

\subsubsection{Valuation the inter band optical absorption type:}

Elliott (1957) proposed a model to decide the main type of the fundamental absorption edge. In this model the absorption coefficient $\alpha(E)$ is examined using a semi-empirical relation after convoluting the total absorption coefficient with a Lorenzian function in the form (Manoogian and Woolly 1984): 


$$
\alpha(h v)=\alpha_{0}\left(\Gamma_{1} / 2\right)^{2} /\left[\left(\Gamma_{1} / 2\right)^{2}+\left(h v-E_{g}+R_{z}\right)^{2}\right]+\alpha_{1}\left\{\frac{\pi}{2}+\arctan \left[\frac{\left(h v-E_{g}\right)}{\Gamma_{c} / 2}\right]\right\}
$$

Where $\alpha_{\mathrm{o}}$ is the absorption peak at ground state energy, $\Gamma_{1}$ and $\Gamma_{c}$ are the full-width at half maximum of Lorenzian and full-width of the continuum excitons, and $R_{z}$ is the free exciton binding energy and $\alpha_{1}$ is the absorption at band gap. The recorded absorption spectrum at room temperature for each studied sample is fitted locally point by point to eq. (7) taking $\alpha_{\mathrm{o}}, \alpha_{1}, \Gamma_{1}, \Gamma_{c}, R_{z}$ and $E_{\mathrm{g}}$ as adjustable fitting parameters. Figure (9) illustrates the measured absorption coefficient fitted using eq. (7). As shown in Fig. (9) absorption coefficient increase in magnitude as $\mathrm{GeO}_{2}$ increases on the expense of $\mathrm{Cr}_{2} \mathrm{O}_{3}$ in lead borate network. Furthermore, the optical absorption shifts towards higher energy indicating an increase in the estimated values of the optical gap which confirms the trend in Fig. (8a). The parameters attained from fitting process are listed in table (2). In this table, comparing the values of the optical energy gaps obtained from eq. (3) (table (1)) and eq. (7) it could be concluded that direct is the most probable transition for the investigated sample.

\subsection{Lorentz dispersion model}

The interaction of propagated light waves of frequency $\omega$ and the oscillating dipoles with resonance frequency $\omega_{0}$ in an optical medium causes a displacement of dipoles as damped oscillators. The damping is a sequence of the fact that oscillating dipoles lose its energy by collision and the damping ability of the optical medium. Furthermore, the damping term together with number of oscillators can alter not only position of the absorption peak but also the broadening of the absorption line. According to the oscillating dipole theory by Lorentz (Roa et al. 1990; Marin et al. 1997; Fox 2003), the dispersion of the absorption index, $k$ is given by:

$$
k=\frac{N e^{2}}{\varepsilon_{o} m} \frac{f \gamma(\omega)}{\left(\omega_{o}^{2}-\omega^{2}\right)+(\gamma \omega)^{2}}
$$

Where $N$ is the number of dipoles per unit volume, $m$ and $e$ are the rest mass and charge of electron in sequence, $\varepsilon_{o}$ the permittivity of vacuum $=8.854 \times 10^{-14} \mathrm{~F} / \mathrm{cm}, \gamma$ the damping factor of the medium and $f$ is the oscillators strength. The calculated absorption indices, of the present samples are fitted to Lorentz model (eq. (8)) with $N$, $f, \omega_{\mathrm{o}}$ and $\gamma$ as fitting parameters as shown in Fig. (10) for sample (4) as an example. 
Indeed, Fig (10) illustrates the coincidence between calculated $k$ and that calculated using Lorentz model (eq. (8)). The composition dependence of calculated values of Lorentz fitting parameters of the presented samples are listed in table (2). In this table the increase of $\mathrm{GeO}_{2}$ in the structural network of $\mathrm{Pb}-\mathrm{B}_{2} \mathrm{O}_{3}$ decreased number of oscillating dipoles from $0.76 \times 10^{24}$ to $0.63 \times 10^{24} \mathrm{~cm}^{-3} \mathrm{~kg}^{-1}$. Furthermore, a decrease of the damping factor $\gamma$ from $1.3 \times 10^{15}$ (sample (1)) to $0.5 \times 10^{15}$ (sample (6)) accompanied by a shift towards higher frequency are argued to the high applying ordering role of $\mathrm{Cr}_{2} \mathrm{O}_{3}$ as a transition metal and are also due to the decrease of the compactness of the material which is argued to the increase of the number of nonbridging Oxygen as a structural defect in the studied samples.

\subsection{Optical dispersion of dielectric constants}

The real component $\varepsilon_{1}$ of the complex dielectric constant could be written as (Moss et al. 1973):

$$
\varepsilon_{1}=\varepsilon_{\infty}-\frac{e^{2}}{4 \pi^{2} C^{2} \varepsilon_{o}} \frac{N_{c}}{m^{*}} \lambda^{2}
$$

Where $\varepsilon_{\infty}$ the high frequency dielectric constant, $C$ is the speed of light and $\frac{N_{c}}{m^{*}}$ is the ratio of free carriers concentration to the free carrier effective mass. Indeed $\frac{N_{c}}{m^{*}}=\frac{\varepsilon_{o} \varepsilon_{\infty}}{e^{2}} \omega_{p}^{2}$ where $\omega_{\mathrm{p}}$ is the plasma resonance frequency for one type of free carriers. According to eq. (9), the slope and intercept of the graphical relation of $\varepsilon_{1}$ against $\lambda^{2}$ yields the values $\frac{N_{c}}{m^{*}}$ and $\varepsilon_{\infty}$. The former attained values are used in turn to calculate the plasma resonance frequency, $\omega_{\mathrm{p}}$. The obtained values of $\varepsilon_{\infty}, \frac{N_{c}}{m^{*}}$ and $\omega_{\mathrm{p}}$ are inserted in table (3). Values of $\frac{N_{c}}{m^{*}}$ in table (3) express the same trend of the refractive index shown in Fig. (6) (assuming a constant effective mass $m^{*}$ ).

The refractive index of the material below the inter-band absorption edge could be calculated using empirical dispersion relation of Wemple-DiDominico (1971) which has the following form: 


$$
n^{2}-1=\frac{E_{o} E_{d}}{E_{o}^{2}-E^{2}}
$$

where $E_{0}$ is the single oscillator energy (average oscillator energy for electrons) and is a measure of the strength of interband optical transitions, $E_{d}$ is the dispersion energy parameter and $E$ is the applied photon energy. Regarding eq. (10) plotting $\left(n^{2}-1\right)^{-1}$ as function of $E^{2}$ and fitting the straight part of the curve in the high energy region yields values of $E_{\mathrm{o}}$ and $E_{\mathrm{d}}$. The former obtained values are inserted in table (3) as function of composition. The dispersion energy parameter, $E_{\mathrm{d}}$, could be considered as a measure to the nearest neighbor cation coordination, iconicity, anion valence and effective number of dispersion electrons of the material and is given as:

$$
E_{d}=\beta N_{C N} Z_{a} N_{e}
$$

Where $\beta$ is a constant and has a values of 0.26 for halides and most oxides (Wemple and DiDominico 1971), $N_{\mathrm{c}}$ is the coordination number of cation's nearest neighbor to the anion, $Z_{\mathrm{a}}$ chemical valence of the anion $\left(Z_{\mathrm{a}}=2\right.$ for oxides) and $N_{\mathrm{e}}$ is the effective number of valence electrons per anion (usually $N_{\mathrm{e}}=8$ ) (Wemple 1979). The calculated values of the coordination number, $N_{\mathrm{CN}}$, for the studied glass using eq. (11) are listed in table (3). Although the obtained values $E_{\mathrm{d}}$ is affected by many parameters such as $\beta, Z_{\mathrm{a}}$ and $N_{e}$ but coordination number still the most leading effect as shown in table (3) where the highest coordination number corresponds to the highest value of $E_{\mathrm{d}}$.

When wavelength is shorter than resonance frequency the role of the lattice is given by (Nassau and Wemple 1982):

$$
n^{2}-1=\frac{E_{d}}{E_{o}}-\frac{E_{l}^{2}}{E^{2}}
$$

Where $E_{l}$ is the lattice oscillator strength. Plotting a graphical relation for $\left(n^{2}-1\right)$ as a function of $E^{2}$ using eq. (12) approaches a straight line with slope $-E^{2}$ and intercept $E_{\mathrm{d}} / E_{\mathrm{o}}$. The obtained values of $E_{1}$ are inserted in table (3) as function of composition.

\subsubsection{Wavelength at zero material dispersion}

The dispersion parameters $E_{\mathrm{o}}, E_{\mathrm{d}}$ and $E_{\mathrm{l}}$ could be used to calculate material dispersion which is an important parameter for the investigated glass. The material dispersion $M(\lambda)$ verify suitability of the investigated compositions to be used in fiber telecommunication. $M(\lambda)$ could be expressed in terms of refractive index, $n$ as follows: 


$$
M(\lambda)=-\frac{c}{\lambda} \frac{\partial^{2} n}{\partial \lambda^{2}}
$$

Differentiating eq. (12) with respect to $\lambda$ gives the material dispersion in terms of $E_{0}$, $E_{\mathrm{d}}$ and $E_{\mathrm{l}}$ and $n$ as follows (Nassau and Wemple 1982):

$$
M(\lambda)=1.54 \times 10^{4}\left(\frac{E_{d} n \lambda^{3}}{E_{o}^{3}}\right)-2.17 \times 10^{3}\left(\frac{\mathrm{E}_{1}^{2} \lambda}{\mathrm{n}}\right)
$$

Figure (12) shows the dependence of the material dispersion, calculated using eq. (14), on applied wavelength in $\mu \mathrm{m}$ for investigated samples. The method of determining wavelength $\lambda_{\mathrm{c}}$ at zero material dispersion, $M=0$, is shown in Fig. (12). The obtained values of the wavelength at zero material dispersion are listed in table (3). Calculation of $\lambda_{c}$ is necessary to balance the material dispersion against waveguide dispersion in optical fibers (Nassau and Wemple 1982). For the sake of comparison values of $\lambda_{c}$ for previously reported values of Borates $\left(\lambda_{c}=1.27 \mu \mathrm{m}\right)$, Silicates $\left(\lambda_{c}=1.56 \mu \mathrm{m}\right)$ and Germinates $\left(\lambda_{c}=1.87 \mu \mathrm{m}\right)$ (Fujino and Morinaga 1997) are added to Fig. (12). Therefore, the studied samples could be considered as appropriate glass to use in transferring data through optical fiber as illustrated in Fig. (12).

\section{Conclusion:}

In the present research the dependence of the structural parameters due to replacement of $\mathrm{Cr}_{2} \mathrm{O}_{3}$ by $\mathrm{GeO}_{2}$ for the compositions $25 \mathrm{~B}_{2} \mathrm{O}_{3}-73.8 \mathrm{PbO}-x \mathrm{GeO}_{2}-(1.2-x)$ $\mathrm{Cr}_{2} \mathrm{O}_{3}(0 \leq x \leq 1.2$ mole $\%)$ is presented. The measured hydrostatic density and calculated molar volume for as prepared bulk samples showed an anomalous behavior which is argued to the presence of $\mathrm{Cr}_{2} \mathrm{O}_{3}$ with its dual role as former and modifier beside the role of $\mathrm{GeO}_{2}$ as former. The same behavior is obtained for the calculated dispersion of refractive index $(n)$. Also, the deconvolution of the peaks of the measured IR spectrum revealed presence of bridging Oxygen up to $x=0.6$ mole $\%$. Furthermore, at higher $x$ in mole \% none bridging Oxygen is the dominant. Indeed, the observed increase of the calculated values of the optical gap $E_{\mathrm{g}}$ are due to the decrease of the calculated localized states in the pseudo gap which means a tendency of the studied network to be more ordered due to the increase role of $\mathrm{GeO}_{2}$ as a former. Fitting of the measured absorption coefficient using Elliott model enabled to distinguish a direct as the most probable transition in the studied samples. On the other hand, coincidence between calculated extinction coefficient $k$ and that 
calculated using oscillator model of Lorentz model is observed. The density of oscillating dipoles showed a maximum at $x=0.2$ mole $\%$ followed by a decrease against the increase of $\mathrm{GeO}_{2}$. The calculated single oscillator energy $E_{\mathrm{o}}$ and dispersion energy parameter $E_{\mathrm{d}}$ are used to calculate the wavelength at zero material dispersion $\lambda_{c}$ for photonic applications. The dependence of $\lambda_{c}$ on the structure showed that the present samples can be used to transmit data through optical fiber in the wavelength range $0.8687-2.1768 \mu \mathrm{m}$.

\section{Acknowledgment}

This project was supported financially by the Academy of Scientific Research and Technology (ASRT), Egypt, Grant No 6405), (ASRT) is the $2^{\text {nd }}$ affiliation of this research. 


\section{References}

Abdel-Baki, M., Abdel-Wahab, F.A., Abdel-Wahab, Radi, A., El-Diasty, F.: Factors affecting optical dispersion in borate glass systems. Journal of Physics and Chemistry of Solids (2007). https://doi.org/10.1016/j.jpcs.2007.03.026

Abdel-Baki, M., El-Diasty, F.: Glasses for photonic technologies. International Journal of Optics and Applications (2013). DOI: 10.5923/j.optics.20130306.02

Abdel-Wahab, F.A., Fayad, A.M., Abdel-Baki, M., AbdelMaksoud, H.: Role of nonbridging oxygen defect in the ionic conductivity and associated oxygen trap centers in lead-borate oxide glass: Effect of structural substitution of $\mathrm{PbO}$ for $\mathrm{Ag}_{2} \mathrm{O}$ and $\mathrm{Li}_{2} \mathrm{O}$ modifiers. Journal of non-crystalline Solids (2018). https://doi.org/10.1016/j.jnoncrysol.2018.06.033

Abdel Wahab, F.A., El-Diasty, F., Abdel-Baki, M.: Dispersion dependence of secondorder refractive index and complex third-order optical susceptibility in oxide glasses. Physics Letters A (2009). https://doi.org/10.1016/j.physleta.2009.08.031

Balda, R., Fernández, J., Sanz, M., de Pablos, A., Fdez-Navarro, J.M., Mugnier, J.: Laser spectroscopy of $\mathrm{Nd}^{3+}$ ions in $\mathrm{GeO}_{2}-\mathrm{PbO}-\mathrm{Bi}_{2} \mathrm{O}_{3}$ glasses. Physical Review $\mathrm{B}$ (2000). https://doi.org/10.1103/PhysRevB.61.3384

Bray, P.J., Leventhal, M., Hooper, H.O.: Nuclear magnetic resonance investigations of the structure of lead borate glasses. Physics and chemistry of glasses 4, 47-66 (1963)

Bray, P.J., O'Keefe, J.G.: Nuclear magnetic resonance investigation of the structure of alkali borate glasses. Physics and chemistry of glasses 4, 37-46 (1963)

Bray, P.J., Lee, D., Mao, D.G., Petersen, G.L., Feller, S.A., Bain D.L., Pandikuthira, D.A., Feil, P., Nijhawan, S.: NQR Studies of the Structure of Glasses and Crystalline Compounds. Zeitschrift für Naturforschung A (1992). https://doi.org/10.1515/zna-1992-1-208

Chelcea, R., Rada, S., Culea, E., Rada, M.: Structural study of ternary iron-leadgermanate glass ceramics. Spectrochimica Acta Part A: Molecular and Biomolecular Spectroscopy (2011). https://doi.org/10.1016/j.saa.2011.03.016.

Culea, E., Pop, L., Bosca, M.: Structural and physical characteristics of $\mathrm{CeO}_{2}-\mathrm{GeO}_{2}-$ $\mathrm{PbO}$ glasses and glass ceramics. Journal of Alloys and Compounds (2010). https://doi.org/10.1016/j.jallcom.2010.06.135

Doweidar, H., El-Damrawi, G., Al-Zaibani, M.: Distribution of species in $\mathrm{Na}_{2} \mathrm{O}$ $\mathrm{CaO}-\mathrm{B}_{2} \mathrm{O}_{3}$ glasses as probed by FTIR. Vibrational spectroscopy (2013). https://doi.org/10.1016/j.vibspec.2013.05.015

Doweidar, H., Oraby, A.H.: Density of lead borate glasses in relation to the microstructure. Physics and chemistry of glasses 38, 69-73 (1997) 
Doweidar, H., Saddeek, Y.B.: Effect of $\mathrm{La}_{2} \mathrm{O}_{3}$ on the structure of lead borate glasses. Journal of non-crystalline solids (2010). https://doi.org/10.1016/j.jnoncrysol.2010.04.036

ElBatal, H.A., ElBatal, F.H., Abdelghanu, A.M.: Gamma Rays Interactions with Strontium Borate Glasses Doped with First-Row Transition Metal Oxides. The Open Spectroscopy Journal (2014). DOI: 10.2174/1874383801408010001

El-Diasty, F., Abdel-Baki, M., Abdel Wahab, F.A., Darwish, H.: Dispersion and thermal properties of lithium aluminum silicate glasses doped with $\mathrm{Cr}^{3+}$ ions. Applied Optics (2006). https://doi.org/10.1364/AO.45.007818

El-Diasty, F., Abdel-Baki, M., Bakry, A.M.: Resonant-type third-order optical nonlinearity and optical bandgap in multicomponent oxide glasses. Applied Optics (2009). https://doi.org/10.1364/AO.48.002444

El-Diasty, F., Abdel-Wahab, F., Abdel-Baki, M., Moustafa, F.A.: Influence of orbital hybridization on Kerr nonlinearity of a heavy metal borate glass: Scaling of polarizability and the imaginary contribution of optical susceptibility. American Journal of Optics and Photonics (2014). doi: 10.11648/j.ajop.20140204.12

El-Diasty, F., Moustafa, F.A., Abdel-Wahab, F.A., Abdel-Baki, M., Fayad, A.M.: Role of $4 p-3 d$ orbital hybridization on band gap engineering of heavy metal glass for optoelectronic applications. Journal of Alloys and Compounds (2014). https://doi.org/10.1016/j.jallcom.2014.03.162

Elliott, R.J.: Intensity of optical absorption by excitons. Physical Review (1957). https://doi.org/10.1103/PhysRev.108.1384

Fox, M.: Optical properties of solids. Oxford university press Inc., New York (2003)

Fujino, S., Morinaga, K.: Material dispersion and its compositional parameter of oxide glasses. Journal of Non-Crystalline Solids (1997). https://doi.org/10.1016/S0022-3093(97)90130-7

Imaoka, M., Hasegawa, H., Ya Sui, I.: X-ray diffraction analysis on the structure of the glasses in the system $\mathrm{PbO}-\mathrm{Si}_{2} \mathrm{O}$, Journal of non-crystalline Solids (1986). https://doi.org/10.1016/0022-3093(86)90011-6

Iordanova, R., Dimitrov, V., Dimitriev, Y., Klissurski, D.: Glass formation and structure of glasses in the $\mathrm{V}_{2} \mathrm{O}_{5}-\mathrm{MoO}_{3}-\mathrm{Bi}_{2} \mathrm{O}_{3}$ system. Journal of non-crystalline solids (1994). https://doi.org/10.1016/0022-3093(94)90397-2

Kamitsos, E.I., Karakassidcs, M.A., Chryssikos, G.D.: A vibrational study of lithium borate glasses with high $\mathrm{Li}_{2} \mathrm{O}$ content, Physics and chemistry of glasses. (1981). Corpus ID: 102464547

Kamitsos, E.I., Karakassidcs, M.A., Chryssikos, G.D.: Vibrational spectra of magnesium-sodium-borate glasses. 2. Raman and mid-infrared investigation of the network structure. Journal of Physical Chemistry (1987). https://doi.org/10.1021/j100289a014 
Khanna, A.: Effects of melt annealing on the mechanical and optical properties of lead borate glasses. Physics and Chemistry of Glasses 41, 330-332 (2000)

Khashan, M.A., El-Naggar, A. M.: A new method of finding the optical constants of a solid from the reflectance and transmittance spectrograms of its slab. Optics Communications (2000). https://doi.org/10.1016/S0030-4018(99)00721-X

Kim, K.S., Bray, P.J.: Nuclear magnetic resonance studies of the glasses in the system $\mathrm{PbO}-\mathrm{B}_{2} \mathrm{O}_{3}-\mathrm{SiO}_{2}$. The Journal of Chemical Physics (1976). https://doi.org/10.1063/1.432125

Leventhal, M., Bray, P.J.: Nuclear magnetic resonance investigations of compounds and glasses in systems $\mathrm{PbO}-\mathrm{B}_{2} \mathrm{O}_{3}$ and $\mathrm{PbO}-\mathrm{SiO}_{2}$. Physics and chemistry of glasses 6 , 113 (1965)

Manoogian, A., Woolly, J.C.: Temperature dependence of the energy gap in semiconductors. Canadian Journal of Physics (1984). https://doi.org/10.1139/p84-043

Marin, G., Rincon, C., Wasim, S.M., Power, C., Sanchez Perez, G.: Temperature dependence of the fundamental absorption edge in CuInTe 2 . Journal of Applied Physics (1997). https://doi.org/10.1063/1.365302

Moss, T.S., Burrell, G.J., Ellis, E.: Semiconductor Opto-Electronics. Butterworths, London (1973)

Moustafa, Y.M., Doweidar, H., EL-Damarawi, G.: Utilisation of infrared spectroscopy to determine the fraction of the four coordinated borons in borate glasses. Physics and chemistry of glasses 35, 104-106 (1994)

Narendrudu, T., Suresh, S., Kumar, A.S., Sambasiva Rao, M.V., Srinivasa Rao, P., Krishna Rao, D.: Spectroscopic and dielectric investigations on the role of molybdenum ions in lead niobium germanosilicate glasses. Journal of non-crystalline solids (2016). https://doi.org/10.1016/j.jnoncrysol.2016.04.008

Nassau, K., Wemple, S.H.: Material dispersion slope in optical fiber waveguides. Electronics Letters (1982). DOI: 10.1049/el:19820306

Priven, A.I.: Evaluation of the Fraction of Fourfold-Coordinated Boron in Oxide Glasses from Their Composition. Glass Physics and Chemistry (2000). https://doi.org/10.1007/BF02732065

Rada, S., Chelsea, R., Rada, M., Bot, A., Aldea, N., Rednic, V., Culea, C.: Electrochemical characterization and structure of tungsten-lead-germanate glasses and glass ceramics. Electrochimica Acta (2013). https://doi.org/10.1016/j.electacta.2013.07.082

Rami Reddy, M., Srinivasa Reddy, M., Veeraiah, N.: Physical properties of PbO$\mathrm{Al}_{2} \mathrm{O}_{3}-\mathrm{B}_{2} \mathrm{O}_{3}$ glasses doped with $\mathrm{Cr}_{2} \mathrm{O}_{3}$. Indian Journal of pure \& applied Physics 44, 446-454 (2006) 
Roa, L., Rincon, C., Gonzalez, J., Quintero, M.: Analysis of direct exciton transitions in $\mathrm{CuGa}\left(\mathrm{S}_{\mathrm{x}} \mathrm{Se}_{1-\mathrm{x}}\right)_{2}$ alloys. Journal of Physics and Chemistry of Solids (1990). https://doi.org/10.1016/0022-3697(90)90162-9

Skuja, L.: Section1. Defects in vitreous Silica and related materials: Optically active Oxygen deficiency-related centers in amorphous Silica dioxide. Journal of noncrystalline Solids (1998). https://doi.org/10.1016/S0022-3093(98)00720-0

Takaishi, T., Jin, J., Uchino, T., Toko, T.: Structural study of $\mathrm{PbO}-\mathrm{B}_{2} \mathrm{O}_{3}$ glasses by $\mathrm{X}-$ ray diffraction and 11B MAS NMR techniques. Journal of the American Ceramic Society (2000). http://dx.doi.org/10.1111/j.1151-2916.2000.tb01588.x

Tauc, J.: Amorphous and Liquid Semiconductors. Plenum Press, London, New York (1974)

Tenny, A.S., Wong, J.J.: Vibrational Spectra of Vapor-Deposited Binary Borosilicate Glasses. The Journal of Chemical Physics (1972). https://doi.org/10.1063/1.1677069

Vaccaro, L.: Atomic and Vibrational Properties of the Non-bridging Oxygen Hole Centers in the Bulk and at the Surface of Silica. (2009) (Ph. D. thesis, Palermo)

Varshneya, A: Fundamentals of Inorganic glasses. Academic Press, New York (1994)

Veeranna Gowda, V.C., Anavekar, R.V.: Elastic properties and spectroscopic studies of lithium lead borate glasses, Ionics (2004). https://doi.org/10.1007/BF02410315

Vijay, R., RameshBabu, P., RaviKumar, V., Piasecki, M., KrishnaRao, D., Veeraiah, N.: Dielectric dispersion and a conduction phenomena of $\mathrm{Li}_{2} \mathrm{O}-\mathrm{Sb}_{2} \mathrm{O}_{3}-\mathrm{PbO}-$ $\mathrm{GeO}_{2}: \mathrm{Cr}_{2} \mathrm{O}_{3}$ glass system. Materials Science in Semiconductor Processing (2015). http://dx.doi.org/10.1016/j.mssp.2015.02.082

Wang, B., Szu, S.P., Greenblatt, M.: Structure and ionic conductivity in Lithium-leadborate glasses. Journal of non-crystalline Solids (1991). https://doi.org/10.1016/0022 3093(91)90383-H

Warren, B.: Summary of the work on atomic arrangement in glass. Journal of the American Ceramic Society (1941). http://dx.doi.org/10.1111/j.11512916.1941.tb14858.x

Wemple, S.H., DiDomenico Jr., M.: Behavior of the electronic dielectric constant in covalent and ionic materials. Physical Review (1971). https://doi.org/10.1103/PhysRevB.3.1338

Wemple, S.H.: Material dispersion in optical fibers. Applied Optics (1979). https://doi.org/10.1364/AO.18.000031 
Table 1: Glass compositions in mole $\%$, ratio $\frac{\mathrm{GeO}_{2}}{\left[\mathrm{GeO}_{2}+\mathrm{Cr}_{2} \mathrm{O}_{3}\right]}$, calculated values of $E_{g}^{d i r}, E_{g}^{i n d i r}$ energy gaps, Urbach energy, $E_{\mathrm{U}}$, Fermi energy, $E_{\mathrm{F}}$, for all the studied samples as function of composition.

\begin{tabular}{|c|c|c|c|c|c|c|}
\hline $\begin{array}{c}\text { Sample } \\
\text { No. }\end{array}$ & $\begin{array}{c}\text { Glass } \\
\text { compositions, } \\
\text { mole } \%\end{array}$ & $\frac{\mathrm{GeO}_{2}}{\left[\mathrm{GeO}_{2}+\mathrm{Cr}_{2} \mathrm{O}_{3}\right]}$ & $\begin{array}{c}E_{g}^{d i r} \\
\mathrm{eV}\end{array}$ & $\begin{array}{c}E_{g}^{\text {indir }}, \\
e V\end{array}$ & $\begin{array}{l}E_{\mathrm{U}}, \\
\mathrm{eV}\end{array}$ & $\begin{array}{l}E_{\mathrm{F}}, \\
\mathrm{eV}\end{array}$ \\
\hline 1 & $\begin{array}{c}25 \mathrm{~B}_{2} \mathrm{O}_{3}-73.8 \mathrm{PbO}- \\
1.2 \mathrm{Cr}_{2} \mathrm{O}_{3}\end{array}$ & 0.0 & 1.61 & 1.33 & 0.81 & 6.47 \\
\hline 2 & $\begin{array}{l}25 \mathrm{~B}_{2} \mathrm{O}_{3}-73.8 \mathrm{PbO}- \\
0.2 \mathrm{GeO}_{2}-1.0 \mathrm{Cr}_{2} \mathrm{O}_{3}\end{array}$ & 0.17 & 2.08 & 1.80 & 0.71 & 6.46 \\
\hline 3 & $\begin{array}{l}25 \mathrm{~B}_{2} \mathrm{O}_{3}-73.8 \mathrm{PbO}- \\
0.4 \mathrm{GeO}_{2}-0.8 \mathrm{Cr}_{2} \mathrm{O}_{3}\end{array}$ & 0.33 & 1.71 & 1.23 & 0.79 & 6.47 \\
\hline 4 & $\begin{array}{l}25 \mathrm{~B}_{2} \mathrm{O}_{3}-73.8 \mathrm{PbO}- \\
0.6 \mathrm{GeO}_{2}-0.6 \mathrm{Cr}_{2} \mathrm{O}_{3}\end{array}$ & 0.5 & 2.17 & 1.94 & 0.61 & 6.47 \\
\hline 5 & $\begin{array}{l}25 \mathrm{~B}_{2} \mathrm{O}_{3}-73.8 \mathrm{PbO}- \\
0.8 \mathrm{GeO}_{2}-0.4 \mathrm{Cr}_{2} \mathrm{O}_{3}\end{array}$ & 0.67 & 2.18 & 1.96 & 0.59 & 6.47 \\
\hline 6 & $\begin{array}{l}25 \mathrm{~B}_{2} \mathrm{O}_{3}-73.8 \mathrm{PbO}- \\
1.0 \mathrm{GeO}_{2}-0.2 \mathrm{Cr}_{2} \mathrm{O}_{3}\end{array}$ & 0.83 & 2.2 & 1.97 & 0.58 & 6.46 \\
\hline 7 & $\begin{array}{c}25 \mathrm{~B}_{2} \mathrm{O}_{3}-73.8 \mathrm{PbO}- \\
1.2 \mathrm{GeO}_{2}\end{array}$ & 1.0 & 2.64 & 2.3 & 0.44 & 6.47 \\
\hline
\end{tabular}


Table 2 Fitting parameters $\alpha_{\mathrm{o}}, \alpha_{1}, \Gamma_{1}, \Gamma_{\mathrm{c}}, R_{z}$ and $E_{g}^{\text {Elliott }}$ of Elliott model, (eq. (7)), Number of dipoles per unit volume, $N$, damping factor, $\gamma$, dipole resonance frequency, $\omega_{0}$, oscillator strength, $f$, for the investigated samples as a function of glass composition.

\begin{tabular}{|c|c|c|c|c|c|c|c|c|c|c|}
\hline $\begin{array}{c}\text { Sample } \\
\text { No. }\end{array}$ & $\begin{array}{c}\alpha_{\mathrm{o}}, \\
\mathrm{cm}^{-1}\end{array}$ & $\begin{array}{c}\alpha_{1}, \\
\mathrm{~cm}^{-1}\end{array}$ & $\begin{array}{c}\Gamma_{1}, \\
\mathrm{meV}\end{array}$ & $\begin{array}{c}\Gamma_{\mathrm{c}}, \\
\mathrm{eV}\end{array}$ & $\begin{array}{c}\mathrm{E}_{\mathrm{g}}^{\text {Elliott }} \\
\mathrm{eV}\end{array}$ & $\begin{array}{c}R_{z}, \\
\mathrm{meV}\end{array}$ & $\begin{array}{c}N x 10^{24}, \\
\mathrm{~cm}^{-3} \cdot \mathrm{kg}^{-1}\end{array}$ & $\begin{array}{c}\gamma x 10^{15}, \\
\mathrm{~s}^{-1}\end{array}$ & $\begin{array}{c}\omega_{\mathrm{o}}, x 10^{15}, \\
\mathrm{~s}^{-1}\end{array}$ & $f$ \\
\hline 1 & 95 & 10 & 10 & 0.11 & 1.92 & 100 & 0.76 & 1.30 & 3.10 & 0.40 \\
\hline 2 & 120 & 6.5 & 3.0 & 0.16 & 2.07 & 70 & 0.8 & 0.80 & 3.50 & 0.31 \\
\hline 3 & 100 & 5.0 & 9.5 & 0.09 & 1.84 & 100 & 0.66 & 0.80 & 3.55 & 0.32 \\
\hline 4 & 95 & 3.6 & 6.0 & 0.20 & 2.27 & 85 & 0.63 & 0.59 & 3.64 & 0.33 \\
\hline 5 & 100 & 7.0 & 7.0 & 0.12 & 2.27 & 95 & 0.6 & 0.56 & 3.62 & 0.33 \\
\hline 6 & 100 & 3.0 & 4.0 & 0.12 & 2.25 & 160 & 0.56 & 0.50 & 3.67 & 0.34 \\
\hline 7 & 100 & 9.0 & 8.0 & 0.08 & 2.78 & 50 & 0.63 & 0.55 & 4.35 & 0.33 \\
\hline
\end{tabular}


Table 3 High frequency dielectric constant $\varepsilon_{\infty}$, ratio of free carrier concentration to the free carrier effective mass $N_{c} / m^{*}$, plasma resonance frequency $\omega_{p}$, wavelength at $\omega=\omega_{p}\left(\lambda_{\omega=\omega p}\right)$, dispersion energy, $E_{\mathrm{d}}$, single oscillator energy $E_{\mathrm{o}}$, lattice oscillator strength $E_{l}$, coordination number, $N_{\mathrm{CN}}$ and wavelength at zero material dispersion, $\lambda_{c}$ for the investigated samples as a function of glass compositions.

\begin{tabular}{|c|c|c|c|c|c|c|c|c|c|}
\hline $\begin{array}{c}\text { Sample } \\
\text { No. }\end{array}$ & $\varepsilon_{\infty}$ & $\begin{array}{c}\frac{N_{c}}{m^{*} \times 10^{55},} \\
\mathrm{~m}^{-3} \cdot \mathrm{Kg}^{-1}\end{array}$ & $\begin{array}{c}\omega_{\mathrm{p}} x 10^{14}, \\
\mathrm{~s}^{-1}\end{array}$ & $\begin{array}{c}\lambda_{\omega=\omega \mathrm{p}} x 10^{3} \\
\mathrm{~nm}\end{array}$ & $\begin{array}{c}E_{\mathrm{d},} \\
\mathrm{eV}\end{array}$ & $\begin{array}{c}E_{\mathrm{o},} \\
\mathrm{eV}\end{array}$ & $\begin{array}{c}E_{l}, \\
\mathrm{eV}\end{array}$ & $N_{\mathrm{CN}}$ & $\begin{array}{c}\lambda_{\mathrm{c}}, \\
\mu \mathrm{m}\end{array}$ \\
\hline 1 & 2.283 & 3.840 & 2.21 & 8.53 & 10.48 & 5.24 & 0.950 & 2.52 & 0.8687 \\
\hline 2 & 2.470 & 5.870 & 0.80 & 22.7 & 13.10 & 6.20 & 0.312 & 3.15 & 1.4129 \\
\hline 3 & 2.970 & 2.680 & 1.62 & 11.63 & 15.03 & 7.24 & 0.245 & 3.61 & 1.4690 \\
\hline 4 & 3.550 & 2.000 & 1.28 & 14.72 & 12.92 & 6.43 & 0.603 & 3.11 & 0.9855 \\
\hline 5 & 2.786 & 1.460 & 1.23 & 15.32 & 13.76 & 6.203 & 0.370 & 3.31 & 1.3131 \\
\hline 6 & 2.580 & 2.254 & 5.03 & 37.46 & 16.50 & 7.32 & 0.115 & 3.97 & 2.1768 \\
\hline 7 & 3.530 & 2.410 & 1.41 & 13.36 & 15.19 & 6.47 & 0.55 & 3.16 & 1.0695 \\
\hline
\end{tabular}




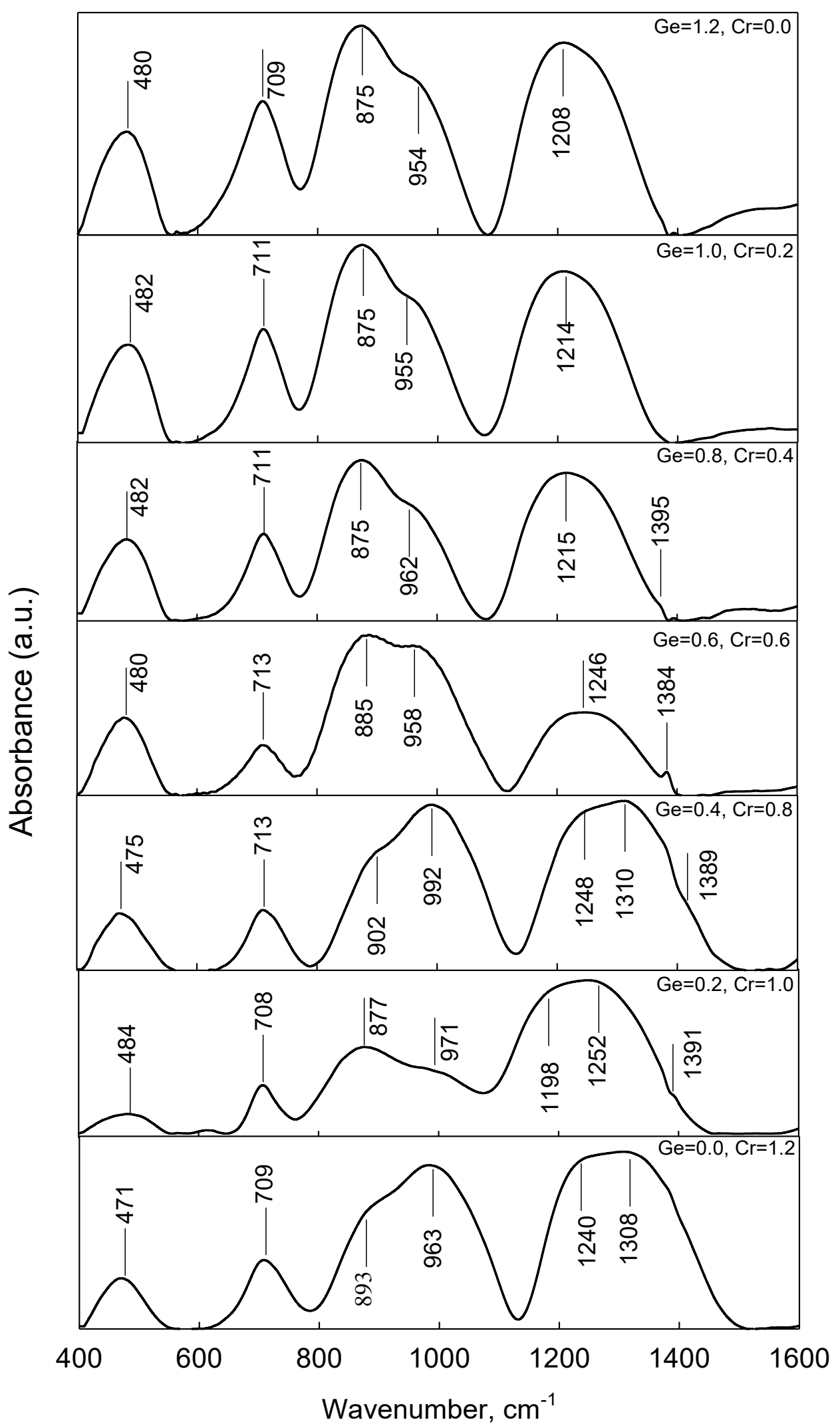

Fig. 1 Infrared absorbance spectra of the investigated compositions $25 \mathrm{~B}_{2} \mathrm{O}_{3}-73.8 \mathrm{PbO}-$ $x \mathrm{GO}_{2}-(1.2-x) \mathrm{Cr}_{2} \mathrm{O}_{3}$ as function of $x$ in mole $\%$. 


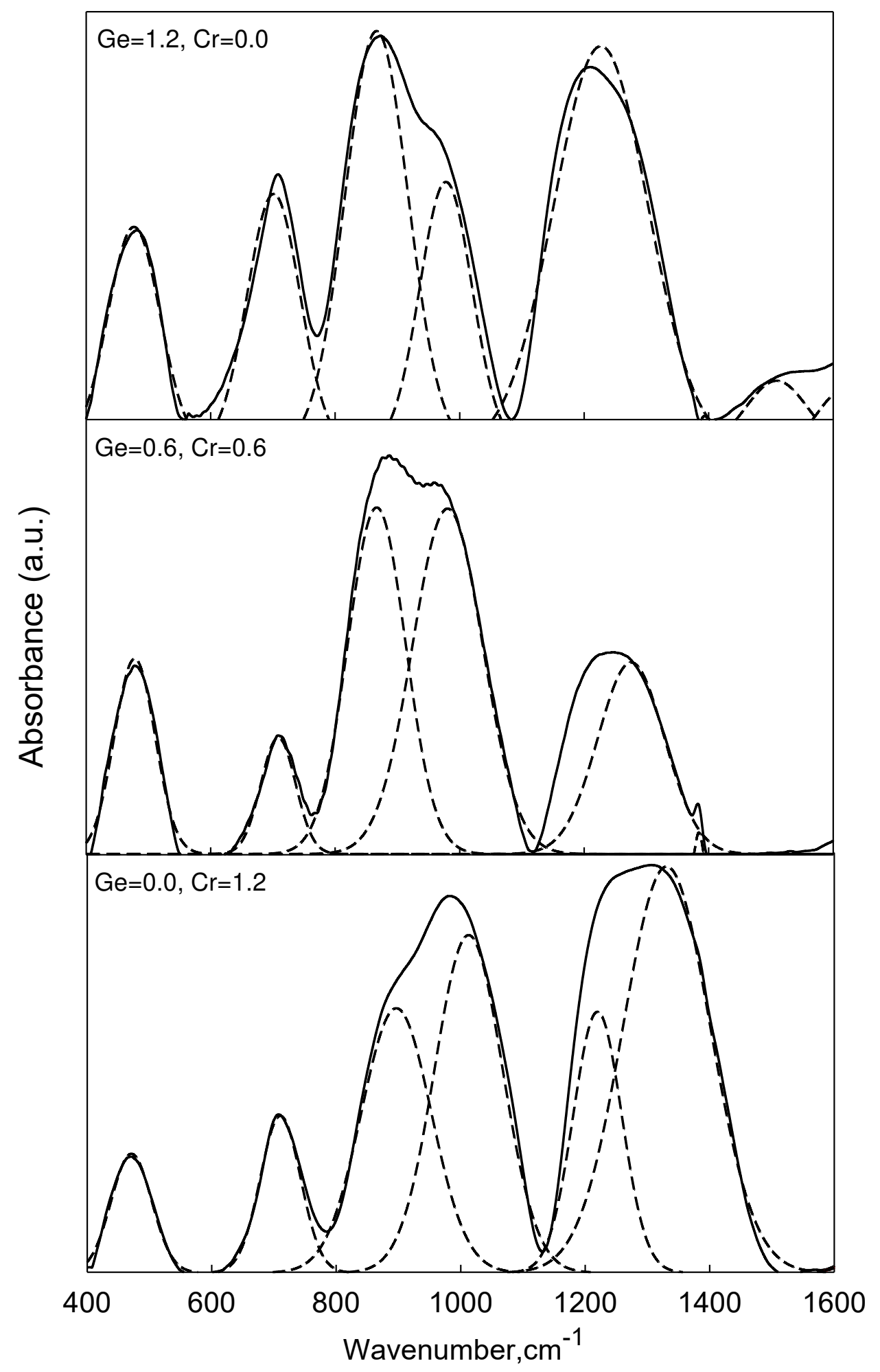

Fig. 2 FT-IR peaks observed in Fig. 1 for compositions $25 \mathrm{~B}_{2} \mathrm{O}_{3}-73.8 \mathrm{PbO}-x \mathrm{GeO}_{2}-(1.2-$ $x) \mathrm{Cr}_{2} \mathrm{O}_{3}$ with $x=0.0,0.6$ and 1.2 mole $\%$ (as an example). The solid lines represent measured spectrum while the dashed lines refer to the deconvoluted peaks. 


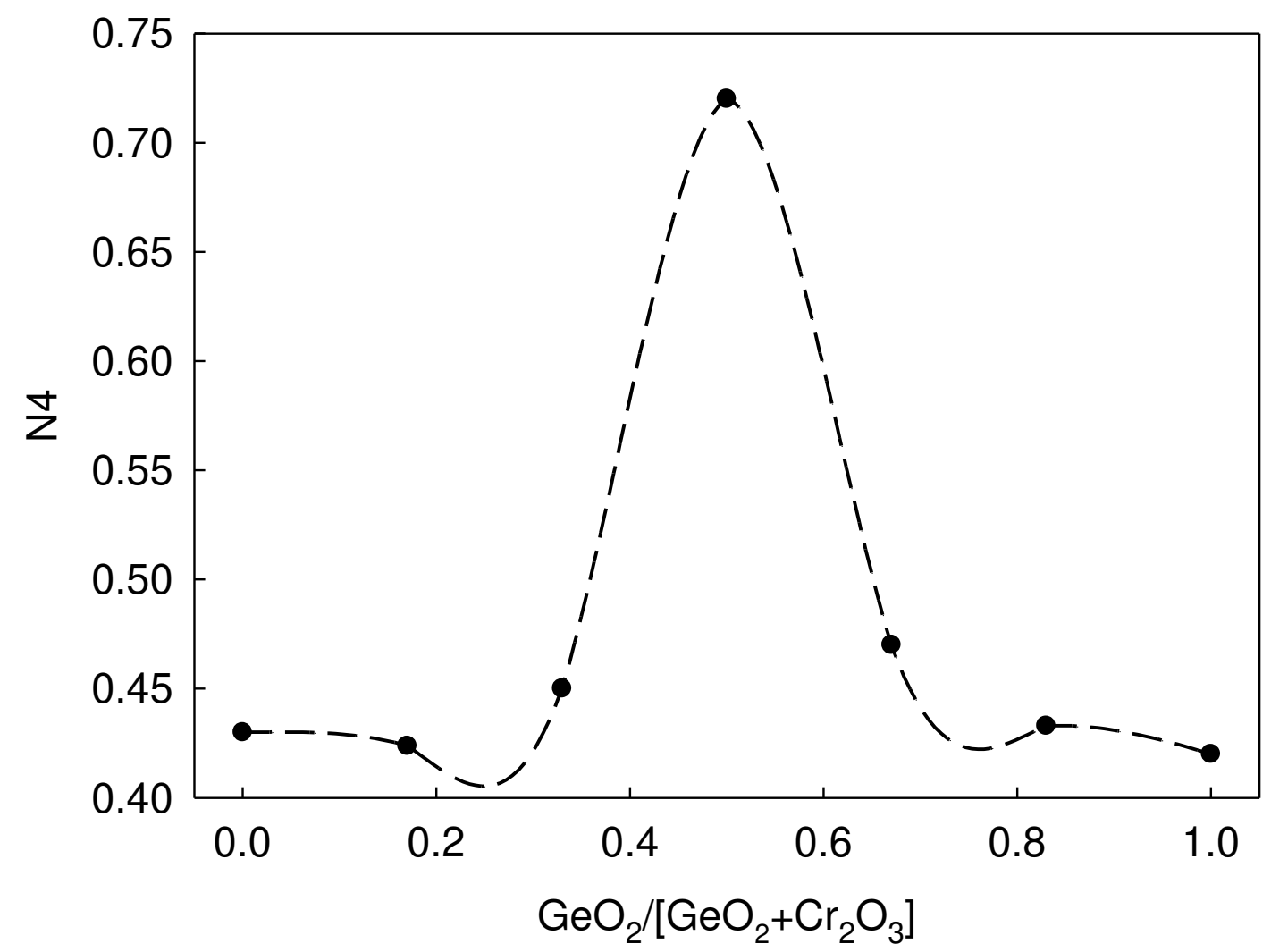

Fig. 3 Dependence of the calculated $\mathrm{N} 4$ on the ratio $\mathrm{GeO}_{2} /\left[\mathrm{GeO}_{2}+\mathrm{Cr}_{2} \mathrm{O}_{3}\right]$. The closed circles represent the raw values of $\mathrm{N} 4$ while the dashed line is a guide for eye. 


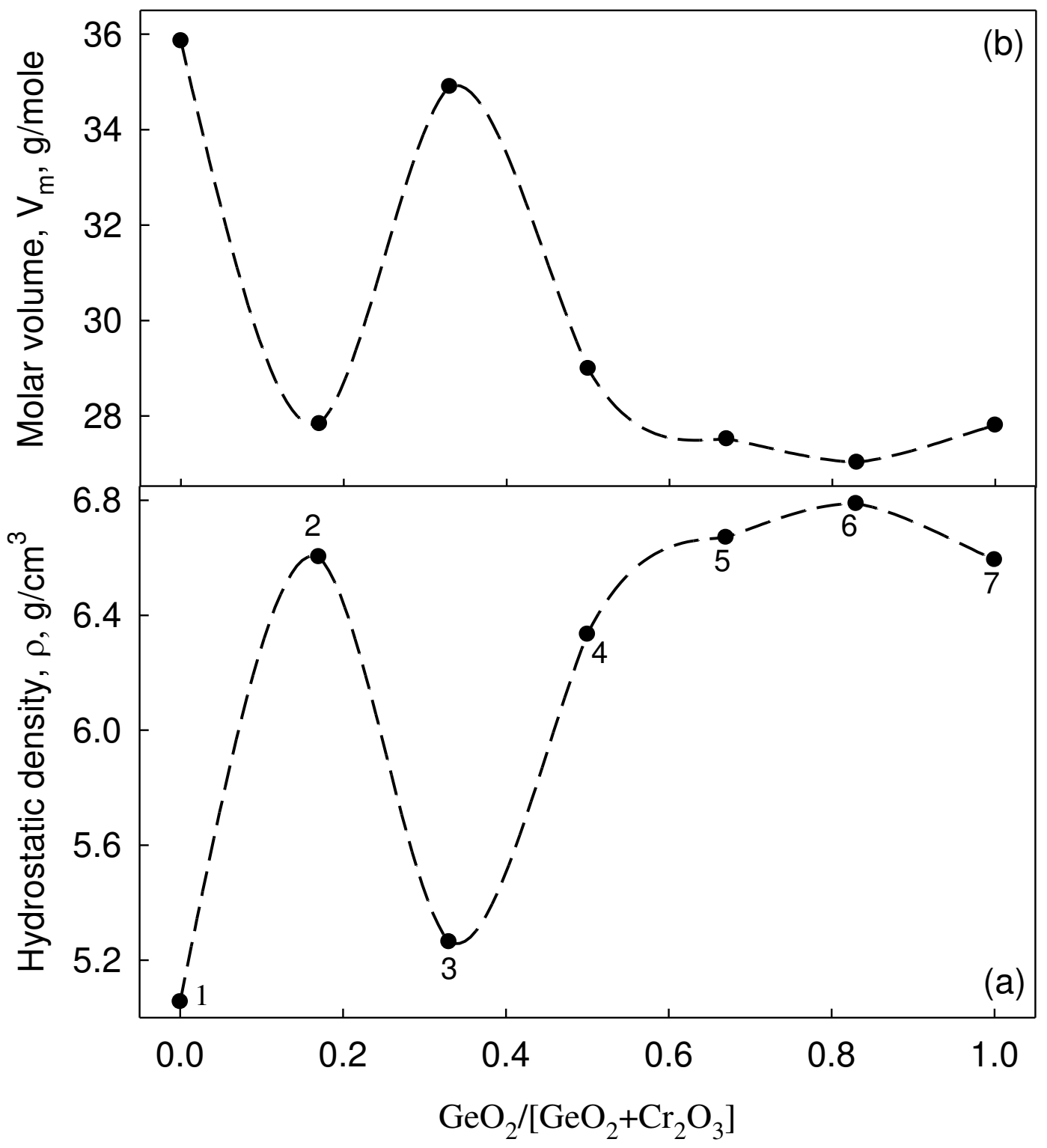

Fig. 4 Dependence of the measured hydrostatic density (a) and calculated molar volume (b) on the ratio $\mathrm{GeO}_{2} /\left[\mathrm{GeO}_{2}+\mathrm{Cr}_{2} \mathrm{O}_{3}\right]$ for the considered samples. The numbers in the figure refer to the sample compositions as listed in table (1). 


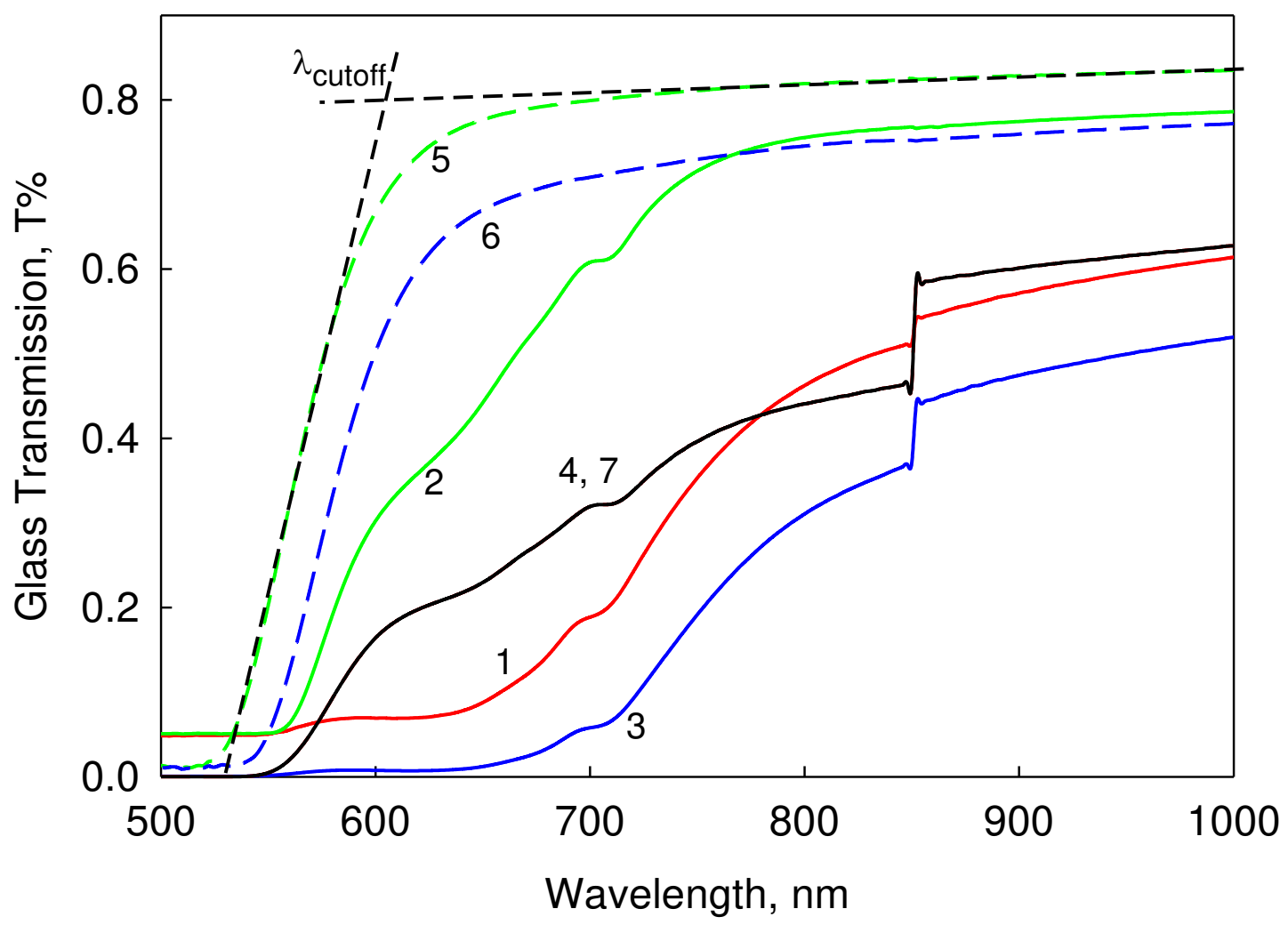

Fig. 5 Measured glass transmission against wavelength for the studied samples. The numbers in the figure has the same meaning as in Fig. 4. 


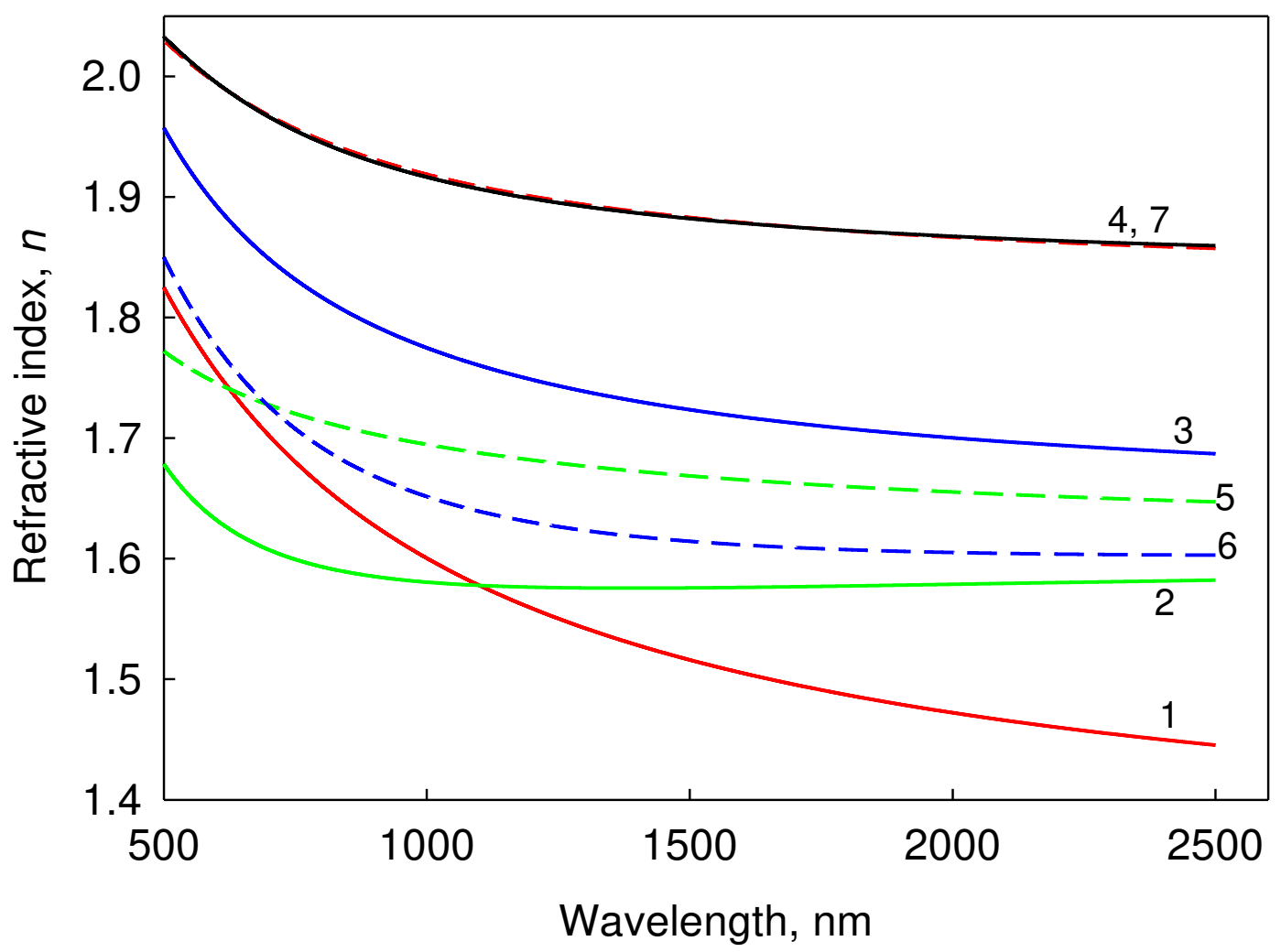

Fig. 6 Cauchy fitted Optical dispersion of the refractive index for all investigated samples. Numbers in the figure has the same meaning as in Fig. 4. 


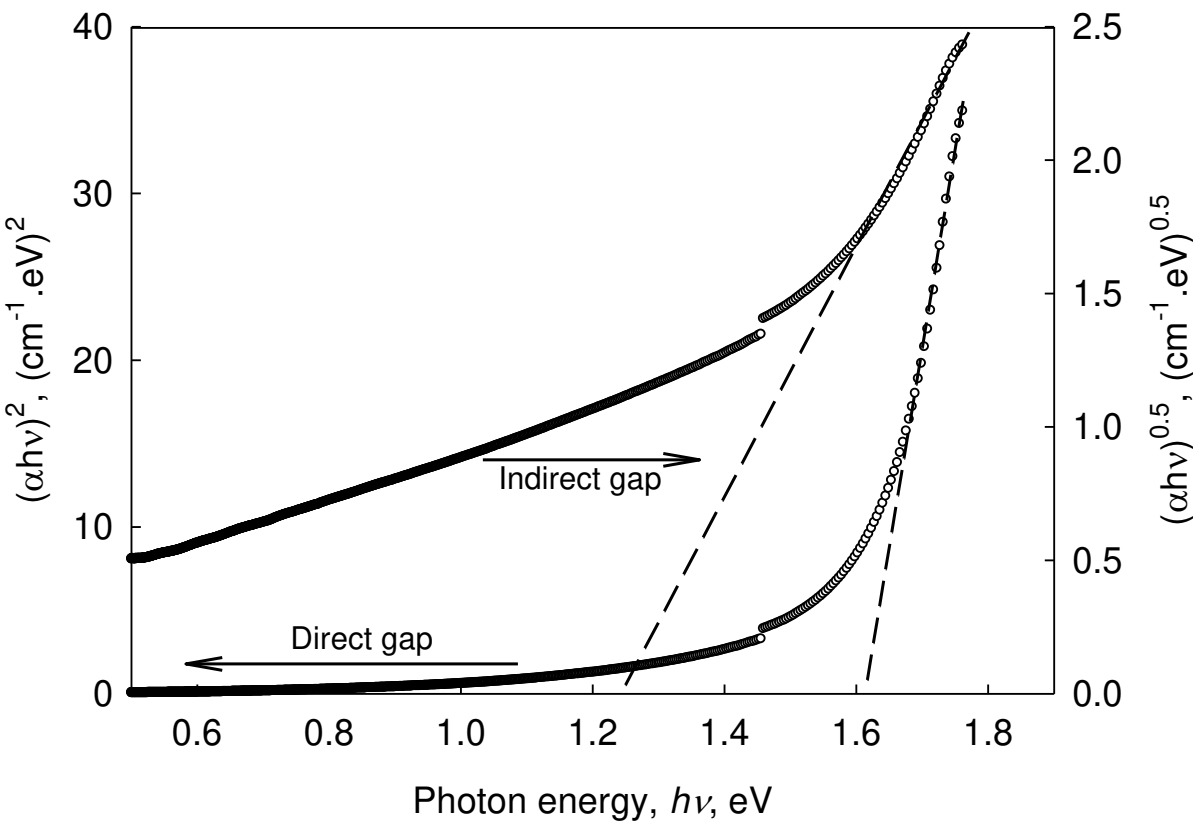

Fig. 7 Calculation of direct and indirect energy gaps. Sample (1) is taken as an example. 


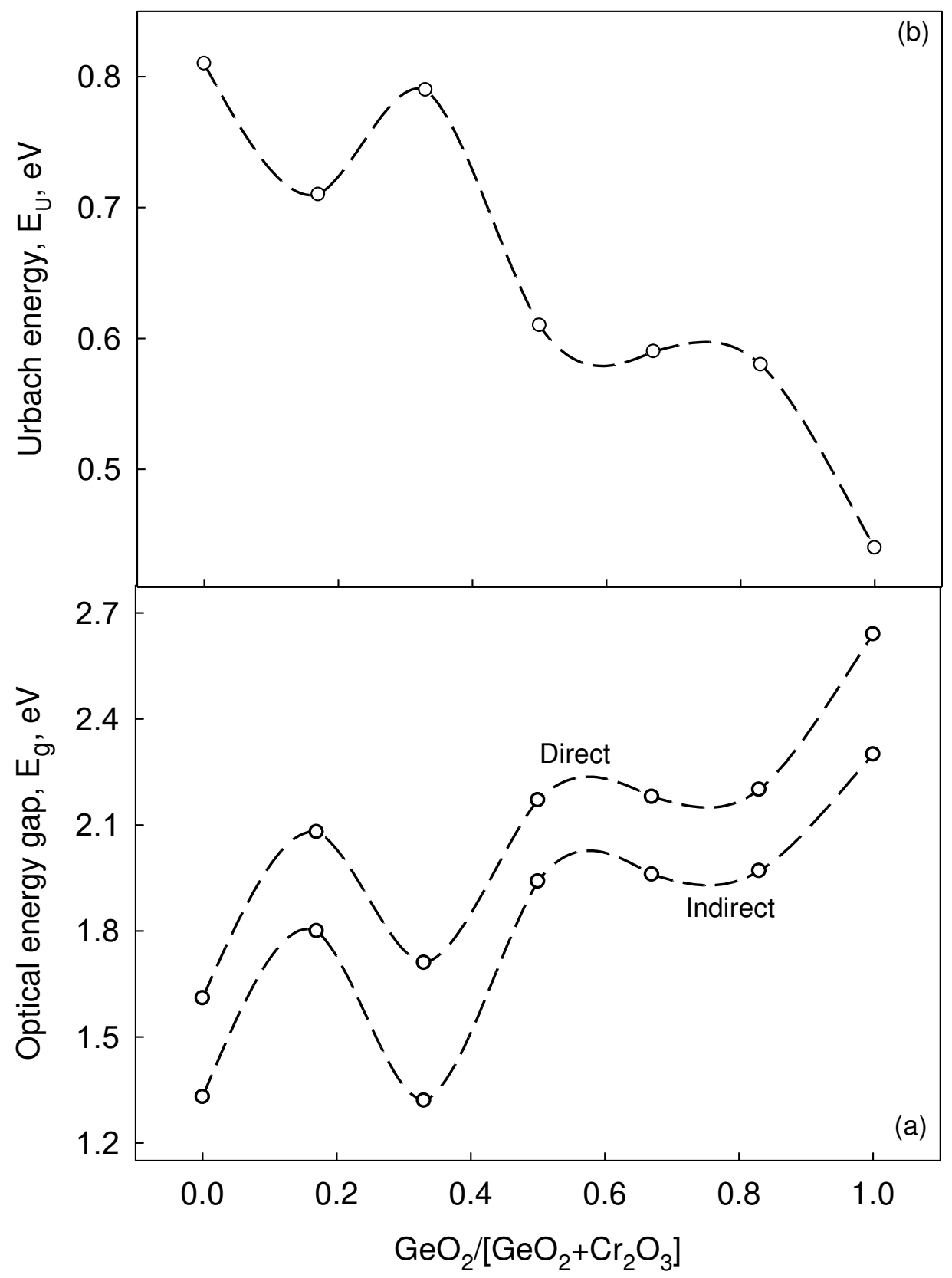

Fig. 8 Dependence of calculated values of direct and indirect energy gaps (a) and Urbach energy, $E_{\mathrm{U}}(\mathrm{b})$, on the compositions. 


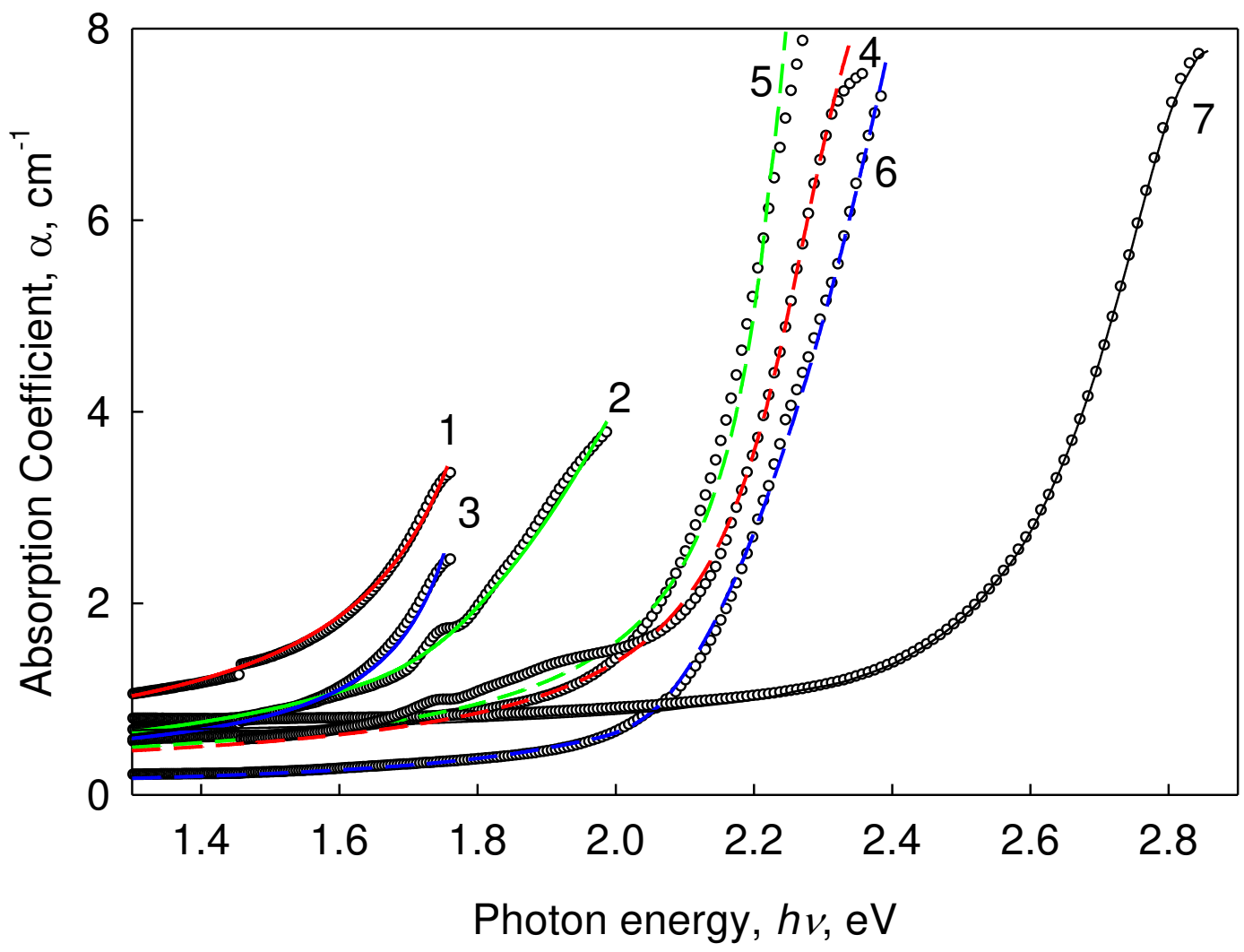

Fig. 9 Fitting of linear absorption coefficient, $\alpha$, using Elliot model (eq. (7)) for all investigated samples. Open circles and solid line refer to the calculated and fitted $\alpha$ in sequence. 


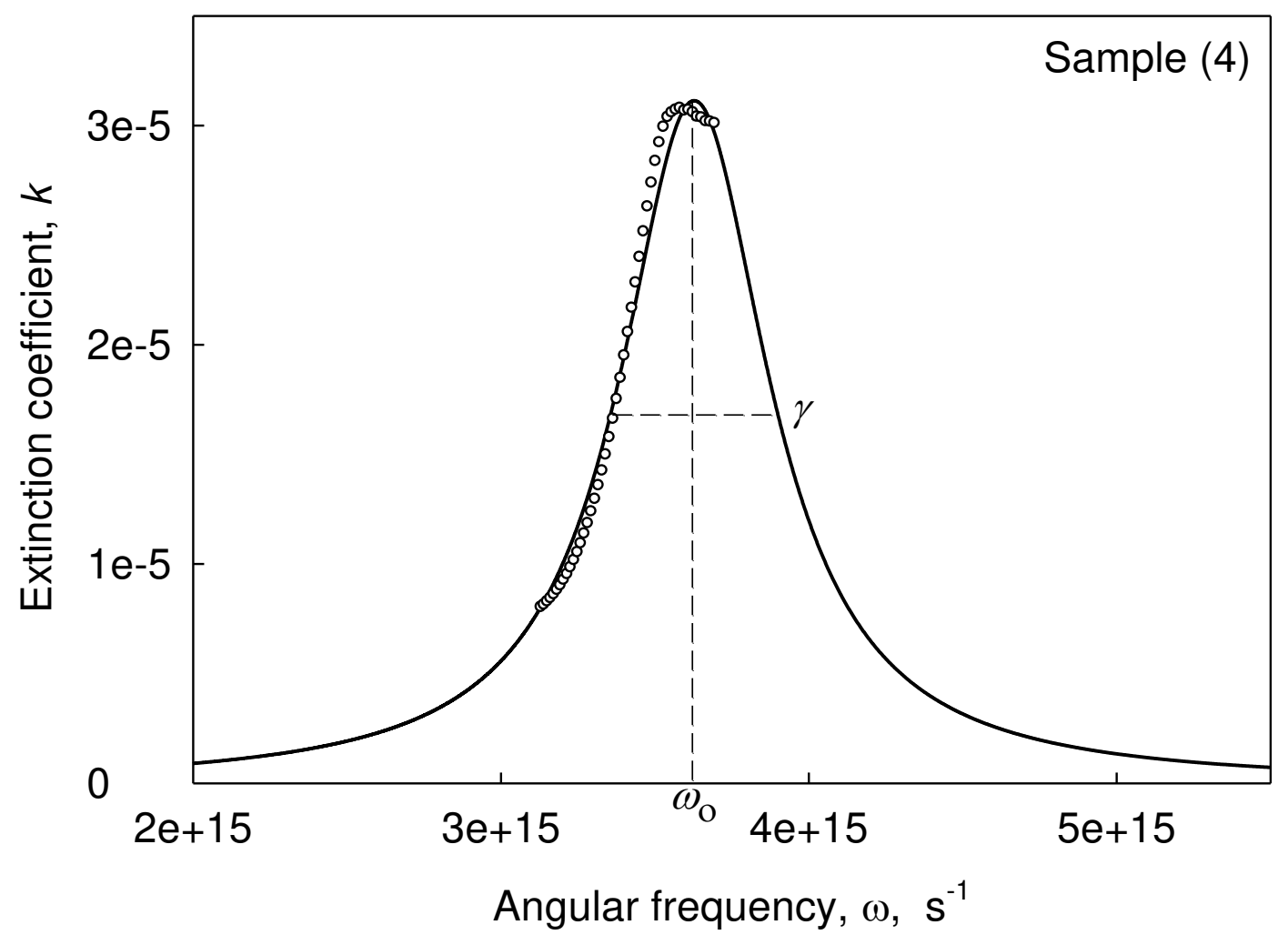

Fig. 10 Calculated extinction coefficient, $k$ (open circles), fitted with Lorentz dispersion model (solid line) for glass sample (4) as an example. 


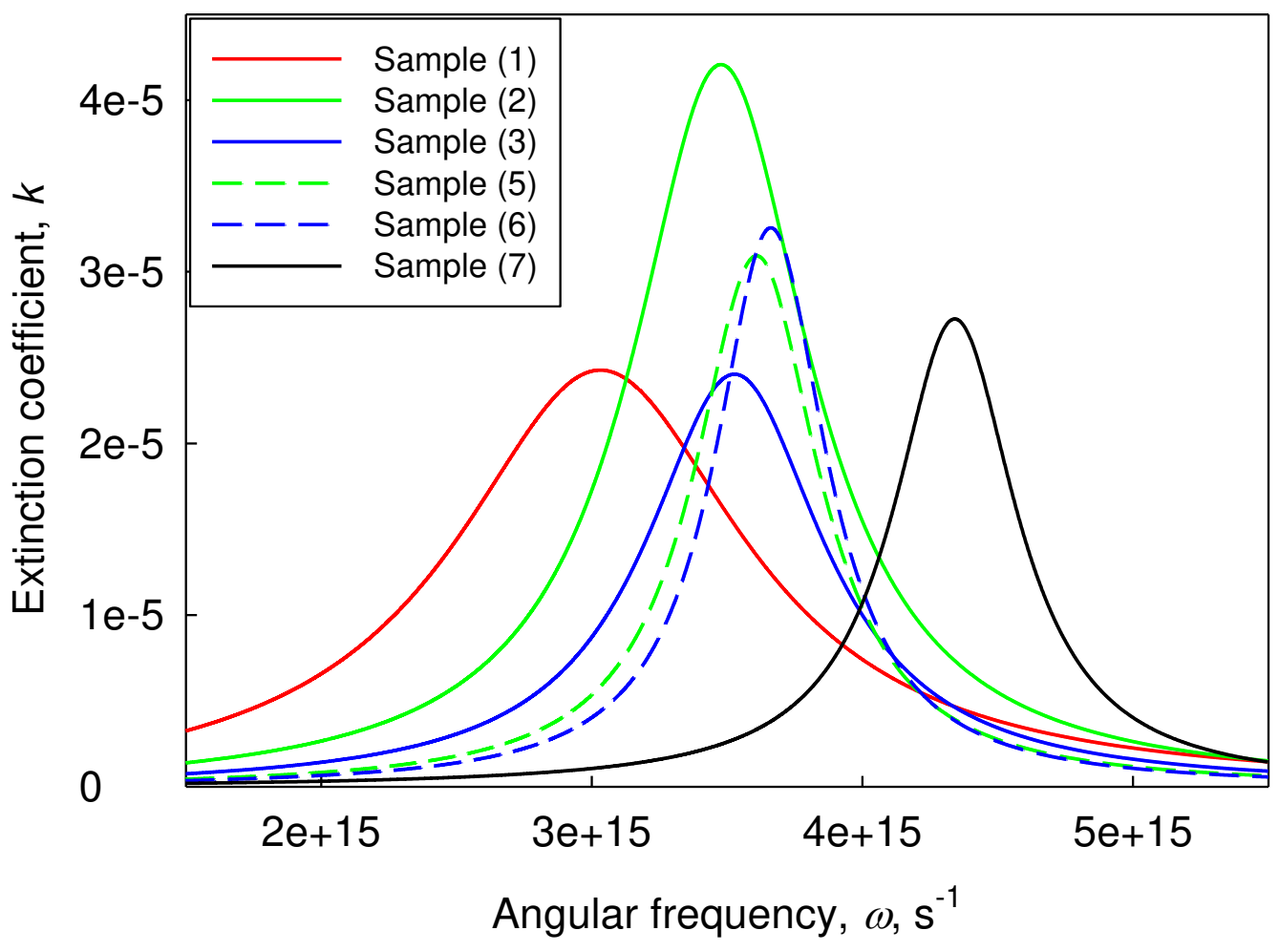

Fig. 11 Extinction coefficient dispersion curves as a function of angular frequency for all studied glass compositions. 


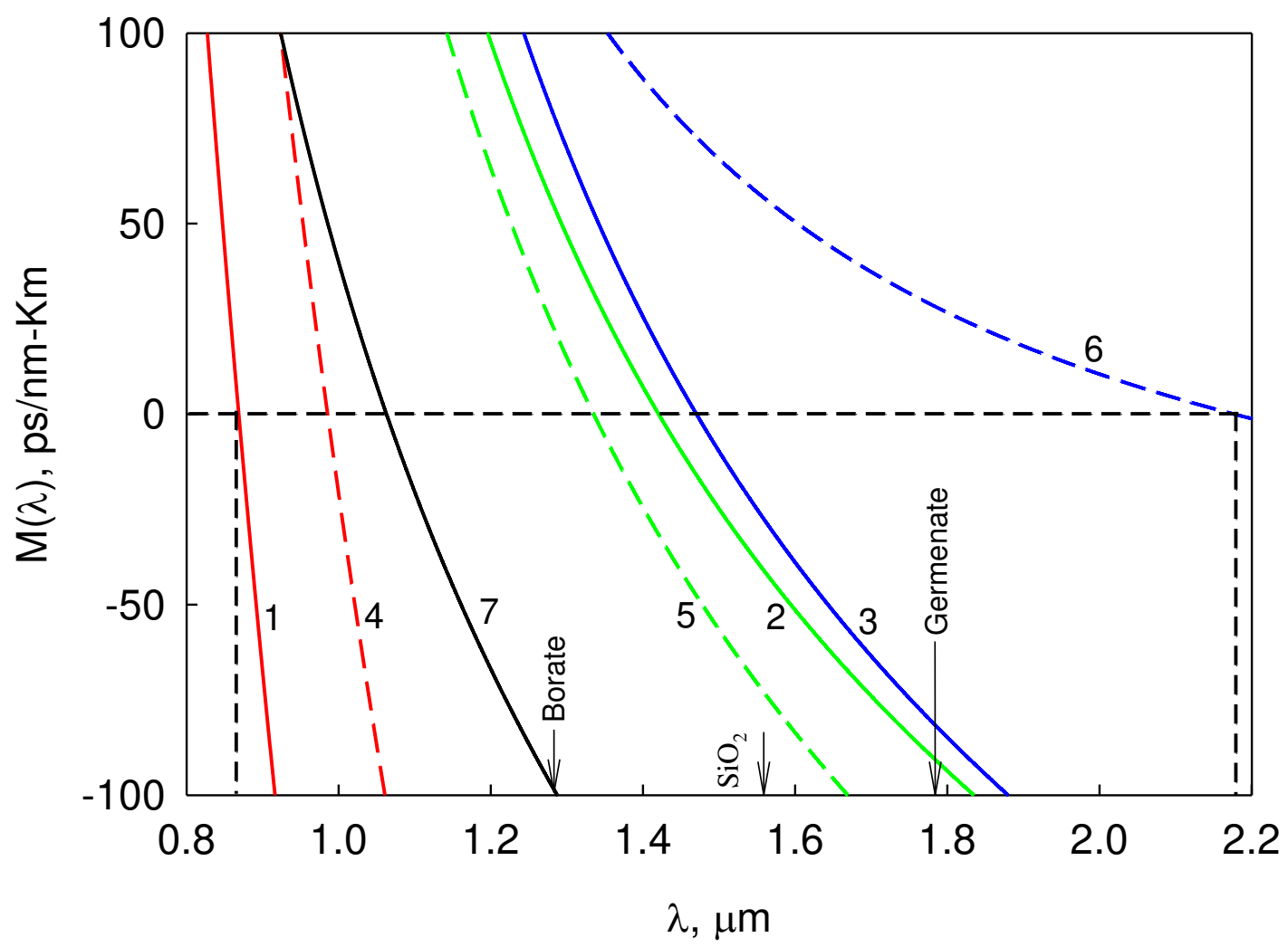

Fig. 12 Dependence of material dispersion on wavelength, calculated using eq. (14), for all investigated samples. Numbers has the same meaning as in Fig. 4. previously reported values of Borates, Silicates and Germinates are added to the figure for the sake of comparison (Fujino and Morinaga 1997). 